\title{
S B 211 $\mathrm{Pg}_{8} \mathrm{M}_{16}$
}

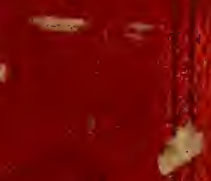

(69) 


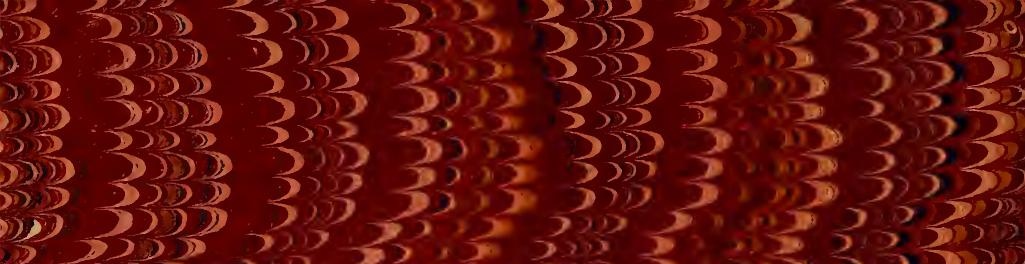

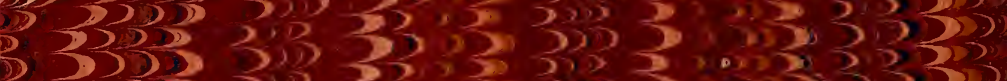

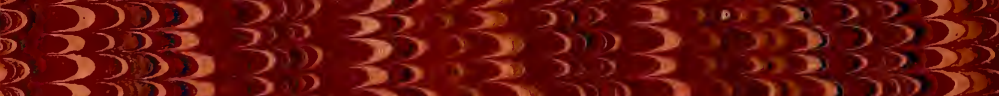

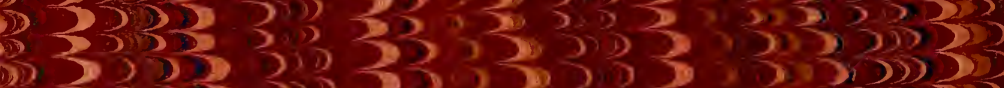

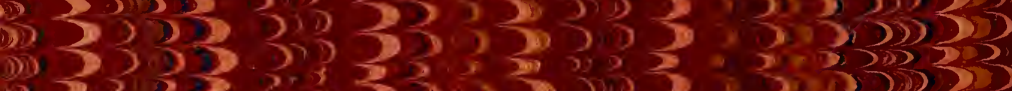

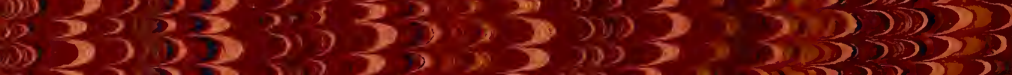

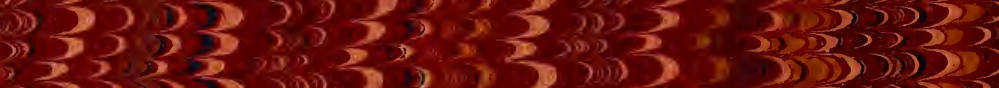



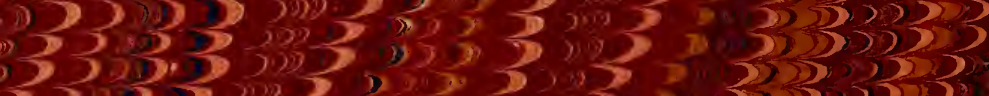

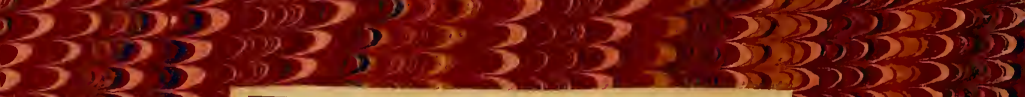

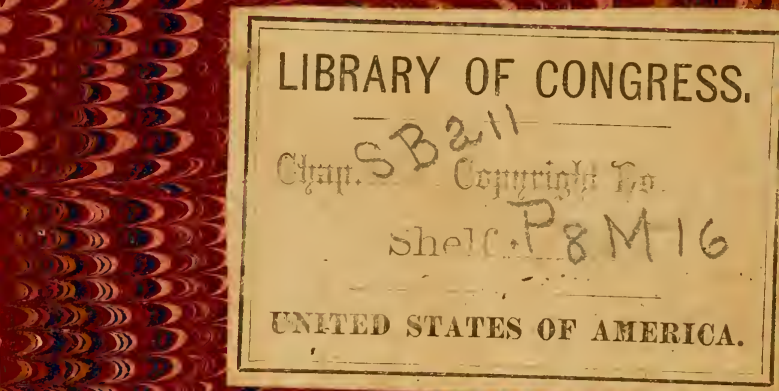
(6) $>>1)$ (i) 330303253

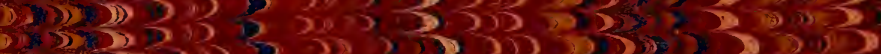

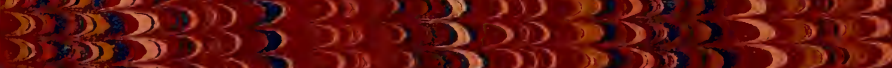

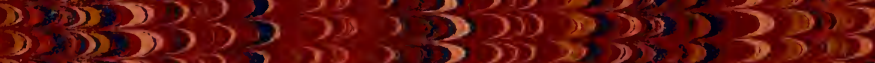

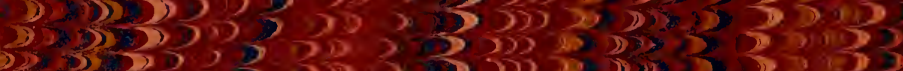

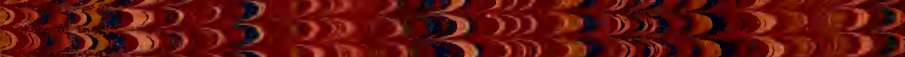

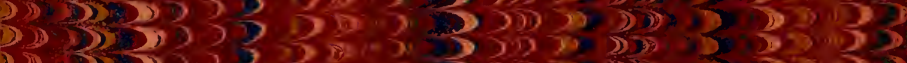

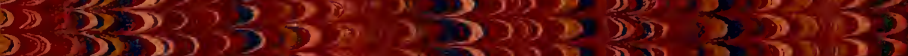

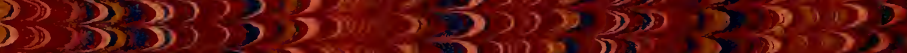

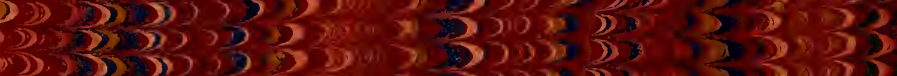

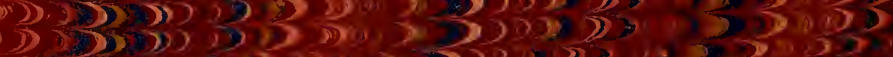
$3 x \geqslant 2$ 


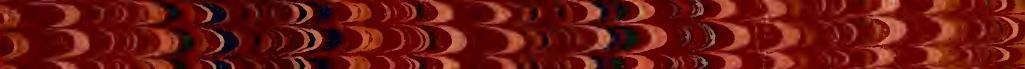

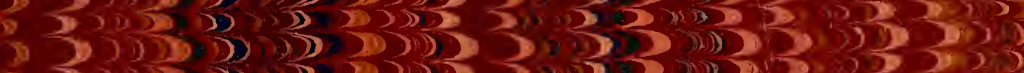

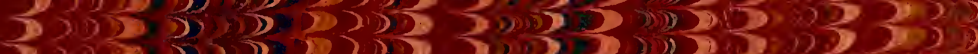

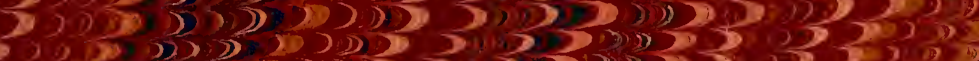

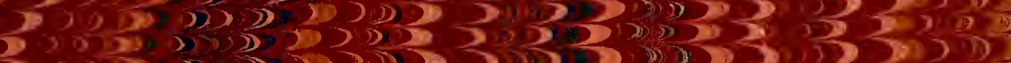

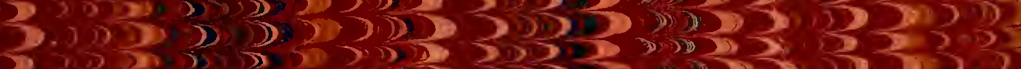

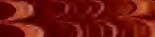

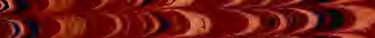
2) 3120309

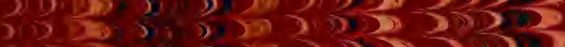
() 52

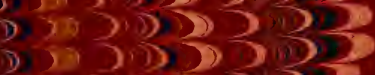

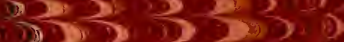

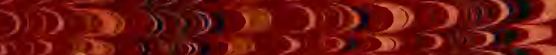
(i) 3032 y 109302 $3 \times 230$

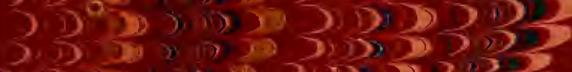
b) 323093 (1) 3233233

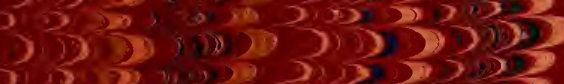

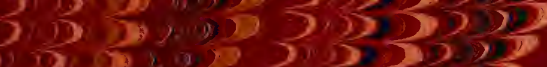

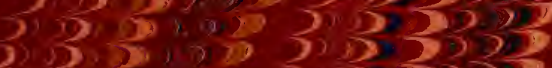
2) $\frac{10}{3}$ 2) 3 2325

(3) 32

$203 .-3$

D. 3

$35=25$ 39 $3,03.53$

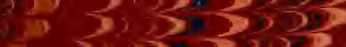
$\frac{20}{3}, \frac{3}{20}-2503$

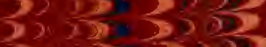
$3 \times \frac{29}{30} \frac{209}{3203}$ D) $>290$ 2 7)

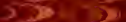
$335 \times 3=2$ 353 कर्या

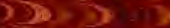

$32-50 \cdot 15$

$350 \times$

3313 3.1300 .02325

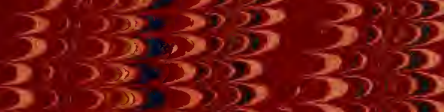
32030323 3) 32032

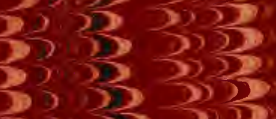

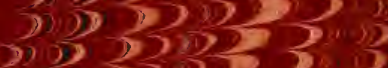
3) 223

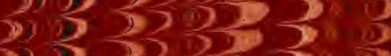

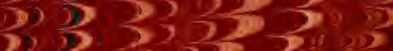

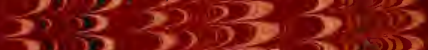
3) 293503013

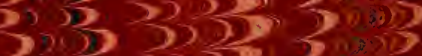

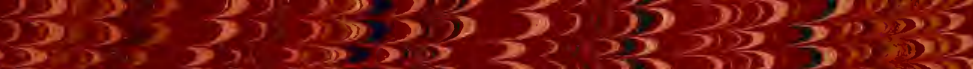



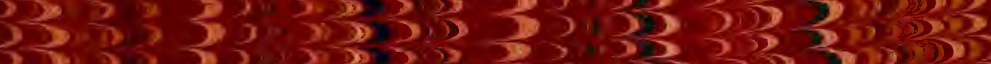

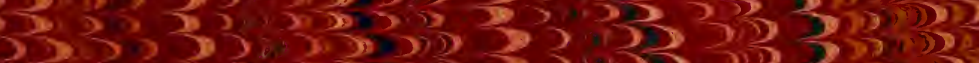

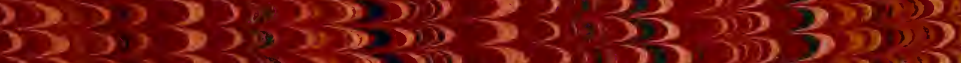

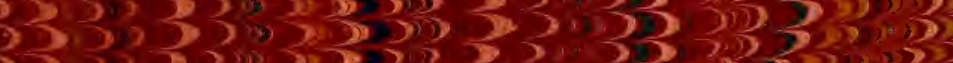

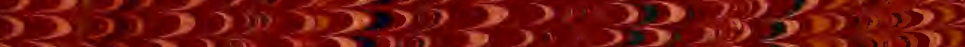

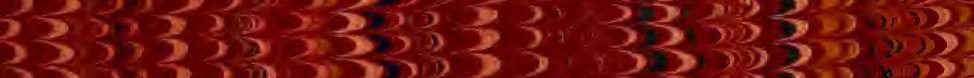

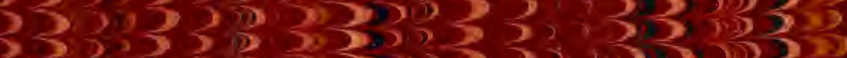

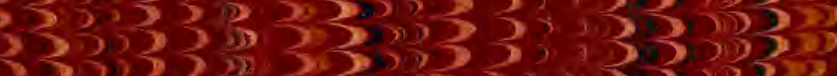

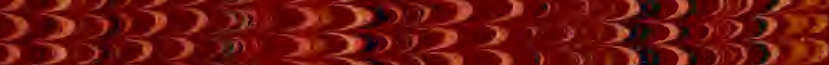

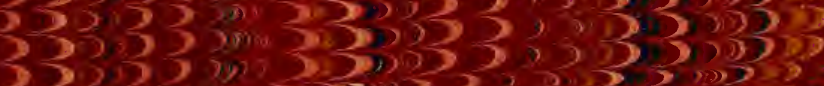

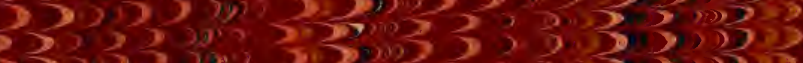

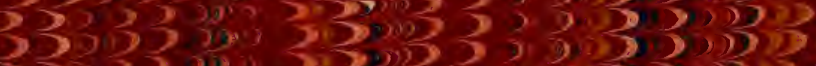

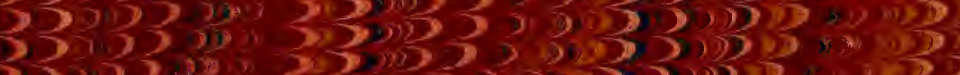

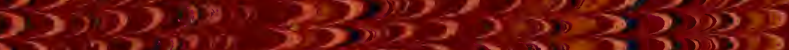

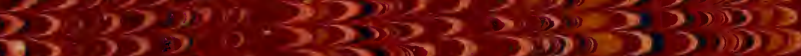

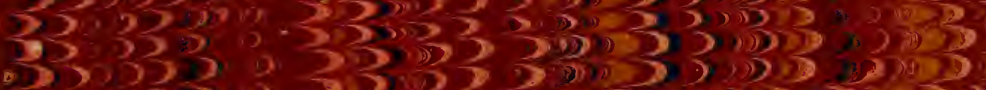









\section{THE}

\section{MODEL POTATO:}

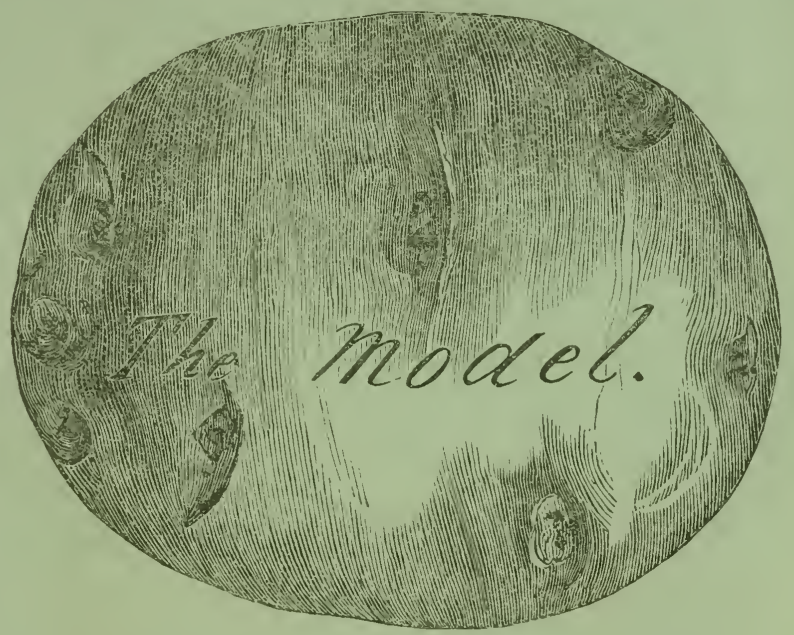

AN EXPOSITION OF THE PROPER CULTIVATION OF THE POTATO; THE CAUSES OF ITS DISEASES, OR " ROTTING ;" THE REMEDY THEREFOR; ITS RENEWAL, PRESERVATION, PRODUCTIVENESS, AND COOKING.

B Y

JOH N M C L A U I N, M. D.

EDITED, WITH ANNOTATIONS,

BY R. T. TRALL, M.D.,

AUTHOR OF" "HYDROPATHIC ENCYCLOP ADIA," "HYGIENIC HAND-BOOK," ETC.

NEW YORK :

SAMUEI R. WEIIS, PUBIISFER, $3 S 9$ BROADWAY.

$$
18 \% ?
$$




\section{T H E}

\section{SCIENCE OF HEALTH,}

\section{A New First-Class Health Monthly.}

T'o educate the people in the Science of Life, which includes all that relates to Preserving Health and to thi Art or RETAIING HEALTH, is the whole object and purpose of this Journal. It will not be the organ of any person: business, or institution, but an independent earnest Teacher of the I.Aws OF LIFE AND HEALTH; the exponent of all known means by which HEALTH, STreNGTH, Happiness and LoNa LifE may be attained, by using and regulating those agencies which are vitally related to HEALTH and the treatment of Drsease including AIR, Light, Temperature, Bathixg, Eating, Drinking, Clothing, Working. Recreation, Exer. cise, Rest, Sleep, Mental Influences, Social Relations, ELECTRICITY, and all normal agents and hygienic materials.

Terms.-\$2.00 a year in advance; Single numbers, 20 cents; ten copies, \$15.00. and an extra copy to agent. Volumes begin in July and in January.

\section{The Phrenological Journal, A FIRST-CLASS MAGAZINE.}

Specially devoted to Ethuology, or the Natural History of Man; Physiology and Anatomy, or the Special Organization and Function of the Human Body; Phrenology, or the Brain and its Functions; Physiognomy, or the Signs of Character exhibited in the Human Face and Form; Psychology, or the Science of the Soul ; Sociology, or Man in his Private and Public Relations; History and Biography, or Man in the Past and in the Present; Science and Art, or the achievements of man in the domains of the practical and the imaginatire; Educatiou, or the Methods of Human Developement and Progressicn; and it is here that Phrenology finds its best and most important field of work. By a positive analysis of individual character it ministers to individual usefulness, designating special aptitude, and indicating the methods by which mental deficiencics may be remedied. It teaches what cach can do hest, and "puts the right man in the right place."

Terms. - $\$ 3.00$ a year in advance. Single Numbers, 30 cents. Ten copies. $\$ 20$, and an extra copy to agent. New volumes begin in July and in January.

Preminus.-Besides the above Club Rates, we are offering the most libera] Premiums, a List of which will be sent on application. Local AGENTs wanted every. where, and cash commissions given. Send P. O. Orders. Address all letters to 
TH E

MODEL POTATO. 


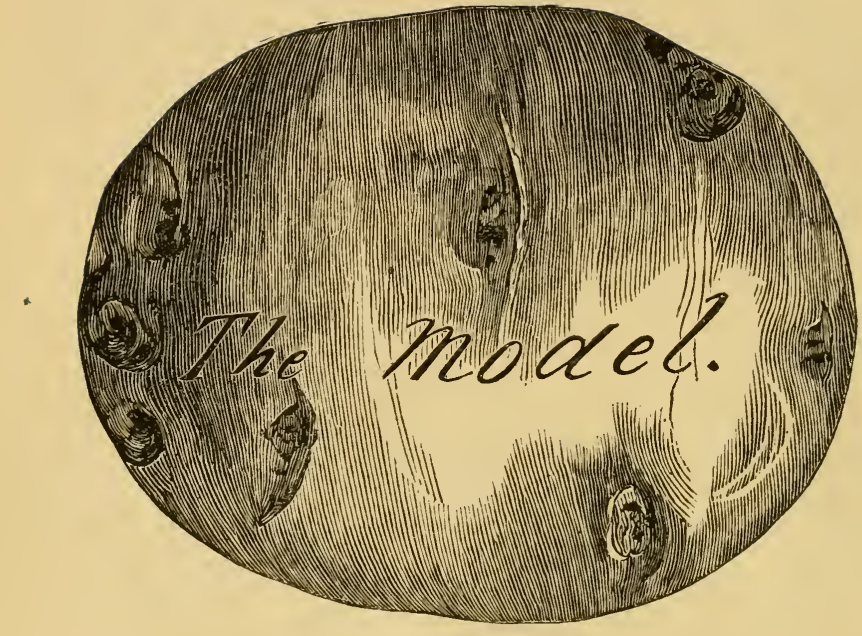




\section{T H E}

\section{MODEL POTATO:}

\section{AN EXPOSITION}

\section{OF THE}

PROPER CULTIVATION OF THE POTATO; THE CAUSES OF ITS DISEASES, OR " ROTTING;" THE REMEDY THEREFOR; ITS RENEWAL, PRESERVATION, PRODUCTIVENESS, AND COOKING.

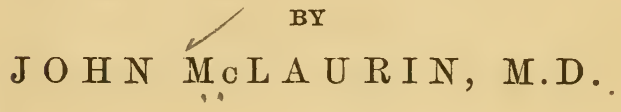
EDITED, WITH ANNOTATIONS,

BY R. T. TRALL, M. D.,

AUTHOR OF "HYDROPATHIC ENCYCLOP EDIA," "HYGIENIC HAND BOOK,"

"WATE-CURE FOR THE MILLION," "THE TRUE HEALING ART,"

" DIPHTHERIA," " SEXUAL PHYSIOLOGY," "sEXUAL PATHOLOGY," "THE TRUE TEMPERANCE PLATFORM," ETC., ЕTC.

NEW YoRK :

SAMUELR. WELLS, PUBLISHER, 389 BROA DWAY.

$$
1872 \text {. }
$$


Entered according to Act of Congress, in the year 1872, by SAMUEL R. WELLS,

In the Office of the Librarian of Congress, at Washington, D. C. 


\section{CONTENTS.}

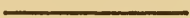

PAGR

INTRODUCTION......................... 5

Generat Proposimions.................... 23

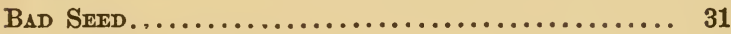

BAD SEed (Continued)..................... 35

VIVISECTION............................ 39

Dwarf Planting....................... 50

Agricultural Chemistry and Chemicat Manures... 53

Crowded Planting....................... 68

Deep Planting....................... 73

Excessive Cotering.................... 78

Diggrng Potatoes...................... 83

Cooknng Potatoes....................... 92

Hramenic CooknNG...................... 97

Tо тне Ротато.......................... 102 



\section{INTRODUCTION.}

BY R. T. TRALL, M.D.

Since the year 1845, when the potato-rot first appeared, causing a famine in Ireland, and incredible suffering in other European countries, the subject of potato-culture has attracted much of the attention of farmers throughout the civilized world; and as the author of this little work has probably been the first to investigate the subject in the light of the laws of nature, and has, in my judgment, propounded the true theory of the diseases of, and remedies for this invaluable esculent, a few words in relation to his preparation and capacity for such a work, may not be uninteresting to the reader.

Thirty years ago the principle of health reform 
was introduced to the world by that masterly work of Sylvester Graham, entitled "The Science of Human Life." Soon after this event a plan or system of medicating all diseases by means of hygienic agencies (commonly but erroneously termed "Hydropathy" or "Water-Cure"), was introduced by a German peasant-Vincent Priessnitz, of Graefenberg. Twenty-eight years ago the editor of this work opened the first hygienic institution in the United States. Twenty years ago a health and medical reformation took permanent form and shape in the organization of the Hygeio-Therapeutic College, which was a few years thereafter chartered by the Legislature of the State of New York.

Health reform and hygienic medication mean notbing more nor less than the application of the laws of organic life to the preservation of health, and the treatment of disease. Their end and aim, their maxim and philosophy, are "a sound mind in a sound body." The cause is preeminently religious, for it contemplates uncondi- 
tional obedience to all of God's laws, as manifested in the organic or the spiritual domain.

Hygienists are therefore obliged to investigate the science of life in its broadest scope ; to learn the conditions of health in all their minutiæ; to understand the causes of disease in all their complications, and to search for natural remedies as no other persons have ever done, whether scientists or physicians. And it was for the purpose of teaching and disseminating information on these subjects among the people, as well as to educate men and women as physicians who would cure the sick without employing medicines that the college aforesaid was established-which, by the way, is still in operation, and the only one of the kind in existence.

John McLaurin, the author of the following work, came to me as a student, and attending the course of lectures of the first college term, graduated at the "commencement." $\mathrm{He}$ had, by reading the "Hydropathic Enclycopedia," the "Water-Cure Journal," Graham's Lectures, and 
other works on hydropathy, hygiene, and dietetics, become a convert to the hygienic system, and entered into the spirit of the health reform with zeal and enthusiasm. He came to the college, not for the purpose of learning a trade or acquiring a profitable business, for these he had already, but for the purpose of procuring information that would enable him to be more useful to others-more successful in teaching, and, if need be, in practicing the principles of the great health reformation.

Soon after receiving his diploma, Dr. McLaurin was employed as a missionary to seek a suitable location for a proposed vegetarian colony. Kansas was selected as the most promising territory for exploration, and Dr. McLaurin spent several months in travelling over the area now known as a State. Kansas was then uninhabited, except in few and distant places, by white people. Indians and animals constituted the principal population, and even these were only to be found in particular "neighborhoods," and were remote from each 
other. Of course our traveller had a rough time of it. Stages were unknown. Hotels were not. Houses had not invaded much of the territory, and even "shəbangs" were scarce.

After roaming over a good part of the territory, camping out in all kinds of weather, exposed to rains, winds, sultry heats, and chilling frosts, and having accomplished the object of his mission, Dr. McLaurin returned to New York. But he was utterly demoralized physically. Apparently his health was ruined forever. He was thin, pale, haggard, coughing severely, and expectorating profusely. In short he had confirmed consumption.

It did not seem to me possible that he could recover, or even live many weeks. I treated him for a few days, until he became rested and comparatively comfortable, when he returned to his home in Canada.

A few months after this the patient I had given over to death astonished me by walking into my office in the image of a well man! 
It was impossible for health reformers long to remain ignorant of the fact that the prevalent system of agriculture was abnormal and vicious in many respects ; that nearly all kinds of food were more or less improper because of improper culture or modes of preservation; that many things grown and sold as food for human beings rere diseased, and consequently unwholesome, and that the same laws of organic life whose infraction occasioned diseases and malorganization in animals and in human beings, prevailed in the vegetable kingdom : and, when disobeyed, occasioned precisely the same disorders and deformities in the grains, fruits, roots, and other vegetable productions which constitute the proper food of man. Hence hygienic agriculture was soon seen to be an indispensable factor in the cause of health reform; for without normal agriculture pure food is impossible, and without pure food no one can live hygienically, except in a degree.

At the time that Dr. McLaurin first gave his attention to hygiene, the potato disease, or "rot," 
which occasioned the "great famine" in Ireland, a few years before, was attracting considerable attention. The potato-producers were apprehensive that the crop was about to fail, and the potato-consumers were alarmed lest an esculent, which has become indispensable to comfort if not to health, was about to be annihilated.

Although many of Dr. McLaurin's co-reformers had given this subject of the potato disease much attention, none of them had entered upon an investigation of the subject systematically and experimentally, as he has done. No hygienist ever doubted that the essential cause, and the only cause, of the deterioration, decay, failure, and rotting of the potato was attributable to an erroneous method of culture, or preservation, or both; for all hygienists know that all diseases, and all imperfections of all living organizations are due wholly to unphysiological conditions-disobedience to vital laws. The only things for them to learn were the particulars-the precise ways in which health conditions were disregarded, and 
the exact means to be employed to restore those conditions.

After Dr. McLaurin recovered his health, he had the good fortune to cure a number of chronic invalids, whose cases had long been considered desperate, some of whom had been abandoned as hopeless by their physicians. These cures were accomplished wholly by means of hygienic agencies, no drugs or medicines of any kind being administered in any case.

Dr. McLaurin, in the honest simplicity of his heart, and with motives purely disinterested and philanthropic, took pains to explain to the neighboring physicians the advantages of "Hygienic vs. Drug Medication," as illustrated in the cases of the remarkable cures to which he referred, expecting probably that he would be applauded or at least tolerated for the good he had done. But his reception was not so complimentary as . he had rightfully hoped. Indeed it was, "on the contrary, quite the reverse." Instead of being praised for well-doing, he was threatened with 
a criminal prosecution for practicing the Healing Art when he was only an irregular physician.

But the cures he performed, though they brought him little fame and less money, rewarded him with that which was better than either or both; with what this world can neither give nor take away. And they enabled hin to realize more intensely the unspeakable importance of a life in accordance with the laws of life, in maintaining health as well as removing the causes of disease, and of applying these considerations more practically to the circumstances which determined the healthy or diseased condition of those productions which are employed as food for human beings; and especially to the potato, then a subject of much discussion. The result had been, a patient, assiduous and elaborate research into the causes of its normal growth and abnormal conditions, until, finally, he has placed in my hands, to be edited and annotated, the manuscript which will constitute the substance of the text of the following pages. 
Within a few years many persons have professed to have discovered the nature and cause of the potato disease and the remedy therefor; but a sufficient answer to all of those pretensions is the fact that the disease still prevails where the remedy has been tried. Like the consumptioncurers who swarm in the cities and infest every village, they do not lessen the statistics of disease nor diminish the bills of mortality.

It requires but a very superficial knowledge of physiology, to enable a person to understand that no drug or nostrum can ever remedy a diseased organism which results from improper culture or imperfect preservation.

It is true that no less than ten different kinds of insects that prey on the potato vine, have been clearly recognized and minutely described by entomologists, and parasitic fungi innumerable have been ascertained to infest the plant, yet they are not the causes but the incidents of its diseases. They are scavengers, and like all creatures of that kind, are always present when 
organic matter is in a state of impurity or of decay. The only protection against insects and parasites is health and vigor.

The potato is peculiar in many respects, and this fact is doubtless the source of many errors which are prevalent respecting the causes of its decay, and the remedial agents or measures which have been recommended. And to this cause may be attributed the discrepancies among authors and agricultural writers respecting the proper method for cultivating and preserving it; to say nothing of the conflicting testimonies and receipts relating to cooking and eating it.

No other production cultivated in this country, if in any country, is subject to precisely the same conditions and influences, nor requires precisely the same management as the potato, in the details; yet all are governed and controlled by the same organic laws and vital principles. I find in agricultural journals and books, and in the catalogues of seedsmen, as much discordance of theory and practice, as I find in the standard 
text-books and journals of the medical profession with regard to the nature, causes, and proper treatment of consumption.

There is, indeed, an instructive similarity in these diseases. The potato disease is exactly analogous to that form of consumption in animals and in human beings known as tuberculous. It is as really a kind of scrofula, as is tuberculosis; and the potato rot is caused by conditions precisely analogous to those which induce consumption and scrofula in human beings, the rinderpest in cattle, the pleuro-pneumonia in sheep, the glanders in horses, the cholera in hogs, and the fatty degeneration in fowls, etc.

And when the farmer, by applying the principles explained by Dr. McLaurin, renovates his potato crop, he may, if he pleases, apply the same principles to the renovation and improvement of all other crops; and if he chooses he may also extend and apply them to the purification and invigoration of his domestic animals. Nor is this all. He may, if he so wills, apply them successfully to 
the prevention of all contagious diseases among human beings, and, to a great extent, of all other maladies.

Perhaps a few words in relation to my personal experience and observation may be a fitting conclusion to these introductory remarks.

For more than a quarter of a century I have been in the constant practice of treating all classes of invalids hygienically; that is, without medicines of any kind, and by means of hygienic agencies, as air, light, temperature, bathing, diet, exercise, rest, clothing, sleep, electricity, magnetism, and in short, all normal influences. As a large proportion of the ills that flesh is heir to are caused by improper and unwholesome articles of food, drink, and condiments, while all morbid conditions are aggravated by them, the dietary constitutes an important feature, and, in many cases, the leading and most important feature of hygienic medication.

I have treated many hundreds of patients for months, who were allowed a mixed dietary, rejecting only the more gross forms of animal food, all 
complicated dishes, and the more pungent and irritating of the articles usually employed as seasonings. I have treated many other hundreds on a vegetarian dietary, but permitting the moderate employment of sugar, milk, and salt. And for ten years past I have treated all classes of invalids on a strict dietary, from which all condiments were rejected, and even the use of sugar and milk (except for infants), discontinued. Although my table has been supplied with a variety of breads, pies, cakes, mushes, soups, puddings, fruits and vegetables, nothing artificial or inorganic has been put in any article of food. Nor has any process of cooking been employed except boiling, baking, or steaming. Nothing has been mixed with or added to any dish or article prepared for or supplied to the table, except soft pure water and heat. No drink is allowed at meals.

In adopting a diet so rigidly simple and natural, my patients soon acquire an excellent appetite; their dyspeptic feelings and morbid 
cravings ultimately disappear, and their instincts acquire a keenness of perceptivity undreamed of before, and only appreciated by the unperverted child or the unsophisticated animal. With a recovery, more or less complete, of the normal perceptivities, comes also the power to discriminate the intrinsic properties and qualities of all alimentary substances; and the plainest food, as unsalted beans, unbuttered rice, unfermented breads, unsugared pies and cakes, unvinegared cabbage and beets, and unpeppered turnips and cucumbers, were eaten with a relish never known to the epicure who uses one or several seasonings with every kind of food he eats.

These patients become excellent judges of the qualities of the articles set before them; hence those who market for such a table must be very discriminating in their purchases. They cannot use the unripe and ill-flavored fruits, the imperfect watery, and unsavory esculents, and the musty, or imperfect flour and meal, nor the unsarory vegetables, that will go down without difficulty 
when well disguised with butter, vinegar, pepper, salt, mustard, radish, catsup, or Worcestershire sauce.

For several years I have supplied my table with berries, tomatoes, green peas, beans, green corn, potatoes, and other roots, fresh from the garden which I have cultivated for the purpose. And, with the fresh and well-matured fruits and vegetables, and the keen and discriminating appetences of my boarders, I have had an unusually favorable opportunity (added to my own personal habits) to learn the difference between a good and a bad, or a perfect and inferior article of food, not only in pleasing the palate, but in satisfying the stomach and improving the health. And I am satisfied that Dr. McLaurin does not lay any too much stress on good or normal food as conducive to human health.

I have also noticed another fact that Dr. McLaurin calls attention to, viz., the difference between potatoes taken from the ground as soon as ripened, and cooked-say in September, and 
those taken from the same field a month or two later. The difference in gustatory properties is very great, and the difference in nutritive value must be correspondingly great; although tastes rendered torpid by stimulating viands, or "seared as with a hot iron," by pungent condiments, may not appreciate the difference.

I hope, therefore, that the hygienic culture of the potato will prove the initiatory step of a general improvement and reformation in all of the culinary modes of cultivating the things which are to be used for the sustenance of human beings ; for health, happiness, and usefulness are intimately connected with good digestion, and for this good food is indispensable.

I have placed the notes I have added in brackets, so that they may be distinguished from the text.

Hygeus Howe,
Florence Hights, N. J., March 1, 1872. $\}$ 



\section{THE POTATO BOOK.}

\section{GENERAL PROPOSITIONS.}

THE first problem to be solved, in relation to

1 the cultivation or propagation of any living organism, vegetable or animal, is the conditions of its normal development and growth; in other words, how can its health be best promoted and maintained?

2. This work is an attempt to explain the proper method of cultivating the potato, increasing its yield, improving its quality, preventing its diseases, in language so plain and simple, that all who are interested as producers or consumers of this important esculent, may readily comprehend the theory taught and the practice or art deduced from it. 
3. The potato "rot" has for many years been a source of serious apprehension, not only with the farmers who raise the crop for market, but also with millions of consumers; and its alarming increase in many parts of the United States and other countries, has caused well-founded fears that the tuber would eventually run out, or cease to be useful as food or profitable as an agricultural production. Such a calamity would indeed be deplorable, for it is not easy to see where a substitute is to be found. But it is confidently believed that this work will afford the necessary information, not only to enable the farmer to arrest the process of deterioration, but greatly to augment the productiveness of the potato, while he restores its quality to its original perfection.

4. Until the potato is treated more rationally than hitherto, and limited to latitudes more natural to it, we shall never know its true value. Its normal range of climate is from thirty-three to fifty-five degrees north and south of the equator; 
or upon elevated tropical lands of the same temperature; and no doubt the nearer forty-five degrees the better. There is no evidence whaterer that the exotic character of the plant is the cause of its decay or deterioration in any locality.

5. The reader may hardly be able to credit at first the statement that the disease of the potato should result from causes seemingly so trivial, and that the cure can be found in rules apparently so simple; yet the changes proposed in its culture almost reverse the present method, and place the edible in normal relations to atmospheric and electrical influences, and in harmony with vital laws so that rapid growth, abundant yield, improved quality are secured.

6. Vegetables and animals possess organs and properties in common, and are subject to the same laws of organization and reproduction. To this statement the potato is no exception. True, the potato is more simple in its structures, and 
less complicated in its functions than an animal. Vegetables have all the vital qualities and instincts of animals. They lack sensibility and mentality. In vital endowments there is no difference whatever. Both are dependent on the same normal conditions and hygienic agencies for proper development and growth. Nor do the farmer's domestic animals-his horses, cattle, sheep, hogs, dogs, and fowls-more surely degenerate and perish than do his potatoes, when subjected to abnormal influences. True, the conditions and modes of propagation and growth vary, in both animals and vegetables, with genera, species, and other circumstances, but the essential and invariable vital laws are the same in all cases.

7. A potato differs from an animal, and from some vegetables, and from some other roots, in the fact that by death it transmits life, the entire tuber being the source of life; and unless this life be transmitted integrally, the progeny will be devitalized, ultimating, in connection with causes 
in debility, disease, and decay. The plan of culture herein recommended prescribes nowostrums and involves no experiments, but removes the causes of deterioration, surely though slowly ; and, the causes being removed, the effects of course cease-the potato disease disappears.

8. Under no circumstances will the method of culture I have explained, fail in arresting decay and promoting vigorous and healthy growth, except through imperfect management, or a partial adoption of it. Those who would have the full benefits of the instruction conveyed in this work should divest themselves of all prejudices and prepossessions, for it is only upon a full observance of all the rules in their entirety, adding nothing and abating nothing, that any important or considerable beneficial results can be predicated. The success of the plan is demonstrable, and the plan itself incapable of deception.

9. Probably the mere reading of the theory 
advanced will convince the intelligent physiologist that the improvements suggested in the cultivation of the potato (which nearly reverse the common method), are vast, and that the results, both as respects the quality and quantity of the crop, must be correspondingly important. Actual practice, however, can only determine the remedial value of the new method to the satisfaction of the farmer. Nature cannot be improved. Her laws cannot be created nor ignored. All that we can do in any department of human action, and all that we need do in raising potatoes, is to remove the causes which conduce to the perversions of her laws.

10. When the present prevalent and erroneous method of planting potatoes is corrected in accordance with the rules herein given, it will then be much better understood than it possibly can be now, how unnatural and injurious this mode has been. Properly cultivated (the effects of existing errors being removed), the potato can 


\section{The Potato Book.}

no more be diseased, than it can be cured under the present abnormal treatment.

11. Though fragmentary parts of the rules herein inculcated are or may have been practiced in different places, the method and system as a whole is claimed to be entirely original, and the result of faithful observation, close study, and careful experimentation. Those who adopt the new method cannot properly impute any fault or failure to it unless they plant the same renewed seed for three successive years.

12. The restoration of the potato to health; its augmented size and increased yield, its better method of preservation, and its proper mode of cooking, increasing, solidifying, and improving it as food, will greatly enchance the profitable results of its cultivation. And as it will be years before the system herein advocated will be generally adopted, those who first take hold of it may realize fortunes. 
13. The author hopes to see this plan adopted soon by all farmers, not only for the sake of having good potatoes for the table, but also for the purpose of arresting a process in one of our most important food-crops analogous to contagion in animals-an achievement of vast moment to the welfare of the human race.

14. There are no less than seven prevalent errors in the common method of potato culture, which tend to the deterioration and destruction of the crop. These will be considered in order, and the remedy for each indicated.

- [The author purposes, as soon as compliance in his plan of potato culture is established, in the recognition of its scientific truthfulness and immense value, to publish a preventive of the rinderpest, or cattle-plague, as the principle involved applies to all contagious diseases alike, whether of vegetables, animals, or human beings.-R. T. T.] 


\section{ERROR 1.}

\section{BAD SEED.}

Although the potato disease is perfectly curable, yet no kind of potatoes will attain large size, or continue productive, if unrenewed from the plum or seed-ball for more than twenty years; and some sorts will not thrive without such renewal for more than half that length of time. The plum is what nature has designed for the reproduction of fresh varieties, and for rejuvenation.

If reproduction is longer neglected, the potato becomes exhausted from old age, and this will ultimate in decay; and if in addition to this the potato is maltreated, the result will be disease. Conscious of such decay, yet ignorant of its cause, planters exchange seed potatoes from distant places. This may improve the quality so far as change of soil and climate may be beneficial; but no remedy short of a full compliance with the law of timely renewal, can restore the plant to its pristine vigor. Without some miracle to dissever 
consequences from their causes, some disease or deterioration might perhaps have been anticipated, when the ages of some kind of potatoes now planted are considered. A persistent neglect of the indispensable physiological law of renewal, not only results in decay, but aggravates other morbific conditions which tend to the production of disease.

Undoubtedly certain localities, soils, seasons, and atmospheric conditions, powerfully tend to develop the disease, which, from other causes, becomes hereditary.

Of the old worn-out potatoes no complete renovation can be expected, either in size, productiveness, or fiavor. They should be superceded by new varieties. Nor can younger kinds generally be improved to the utmost without regard to the law of renewal.

Of the various kinds of potatoes under twenty years of age, few are so badly affected that they will not speedily yield to the power of renewal, so far as the disease is concerned, when due attention 
is paid to the rules of normal culture. The potato, as is the case with other vegetables, and with animals, is more easily cured before than after vitality is in a state of decline from old age.

[I have before me a Prize Essay on the Cultivation of the Potato, by D. A. Compton, of Hawley, Pa., to which a premium of $\$ 100$, offered by W. T. Wylie, of Bellefonte, Pa., was awarded. In this Essay there is no allusion to the subject of renewing the crop from the plum; nor can I find any mention of it in any of the works on potato-culture, reports of Farmers' Clubs, nor Agricultural Journals which I have been able to obtain. I have, however, heard incidentally that some amateur farmers have tried this experiment with excellent results. If the idea of reproducing the potato in this way, and thus renovating or renewing its vitality, is not original with Dr. McLaurin, I think he is justly entitled to the credit of discovering and promulgating its necessity. -R. T. T.] 


\section{REMEDY 1.}

When ripe, pick from the best specimens or kinds of potato vines the largest plums, or berries; dry and preserve them from dampness and frost. In the spring sow them in the nursery. Treat them afterwards as you do your other potatoes, a la regime; and from the product, in two or three years, you may select the best kinds for field planting.

This is all that is necessary to say on this subject. But, in the details of the process of renewal there is an ample, and, to most persons, a novel field for experiment. One may be more skilful than another, and, perhaps, more so than I have been; hence I purposely avoid details, preferring to leave the matter open for every one's unbiased experience and investigation; as any person may, by attentive observation and careful study, originate or perfect some useful feature, or make some valuable discovery. If you are obliged to select from the stock of seedsmen, 
be sure and obtain the best specimens. One method, however, of preserving the plums, I will mention, which is in sand or sawdust. They may be sowed in rows, like turnips, thinning them when too thick, but never replanting those which are pulled off.

-[The seeds of the plums, like those of melons and cucumbers, may be squeezed out, dried, and preserved in paper. In the spring they may be sowed in drills, like onions or turnips. They should be kept thoroughly weeded, and have room enough to prevent them from coming in contact in the process of growth. -R. T. T.]

\section{ERROR 2.}

\section{BAD SEED.}

THE omniginous and promiscuous method of planting the potato is another cause of deterioration and disease. Mixing together for seed potatcies any and every kind, good, bad, old, young, 
indiscriminately, affects the crop as deleteriously as a similar process would the breeding of animals. No good crop can ever permanently come of such planting, however favorable the season may be, or however rich the soil, or skilful the tillage.

[I am not aware that any other seed, whether of grains, fruits, or roots, is treated in this way by farmers; and there is no reason in the nature of things, certainly none in the laws of reproduction, why potatoes should be. They are surely no exception to vital or organic laws. Our farmers seem to understand very well that, if they would have the best crops of wheat, or corn, they must have seed in its most perfect condition. The rule in relation to corn, to select the best kernels from the best rows of the best ears of the best hills, is not exaggerated in the least. And it applies to seed potatoes as well as to seed corn. Indeed it applies to every living organism that it is desirable to have in its best possible condition. The great truth that the plant, the tree, the 
animal, and the man, is but the unfolding of the seed or egg, and that its conditions, or constitutional qualities must inevitably attach to the individual organism developed from it through life, may some day be realized, and then agriculture may be placed on the hygienic basis. The more progressive physiologists are beginning to learn that ante-natal conditions are of prime importance in the rearing of normal offspring-a law which applies to the seeds and eggs as well as the embryotic life, of the future beings. Whoever saw a farmer select the seed of an apple, a pear, a peach, a plum, a cherry, a gooseberry, a currant, a pumpkin, a squash, a watermelon, or a cucumber, except from the largest, best-flavored and most smooth and solid specimens he could find? Probably such a thing was never heard of, and yet he jumbles big and little, sound and rotten, smooth and rough, sprouted and blighted potatoes together for planting, and expects a good crop, but gets the fruits of what he sows !R. T. T.] 


\section{REMEDY 2.}

In choosing the proper kinds of potatoes for planting, it should be remembered that the most profitable, if not the sweetest, grow large in size; in shape they are round like apples, pears, peaches, or eggs, or a combination of them all; in color they are red, pink, or white, or all three colors intermingled; the eyes are few and not sunken, but protuberant. The potato should be hard, heavy, dry, and sweet, and of course, wholesome ; and when perfectly healthy, it will have all these qualities.

While the selections are made in conformity to the above rules, no injury results from planting different varieties in the same field, unless the disparities in age and quality are extreme; size being always attainable by a close adherence to the rules.

It is not denied that some sorts of potatoes which vary from those above described in shape and color may be good; but it is maintained that 


\section{The Potato Book.}

those answering this description, upon the whole, are the best.

\section{ERROR 3.}

VIVISEOTION.

Cutting the seed is one of the chief causes of the potato disease. The method of gouging out the germinal part, or eye, or slicing the potato into pieces for planting, has long been practiced by nearly all planters, but with what result let the present deplorable prevalence of the potato rot testify.

The sundering of the bud from the body of the tuber, under the impression that such mutilated fragments will produce healthy and vigorous fruit, is most fallacious and absurd, and has no parallel among the many blunders of agriculturists. This unnatural severance by division dissipates the vital forces of the seed, and debility of the offspring is the inevitable consequence. In proportion as tho unity of the tuber is destroyed by multiplied sec- 
tions, so the progeny derived therefrom is enfeebled and rendered liable to disease. To suppose that this process of mutilation economizes seed, and produces more bushels than the sound potatoes would if planted whole, is a delusion that has probably no parallel in false physiology. Instinct never suggested so absurd a notion ; reason never conceived it; science never taught it; nor did experience ever confirm it. It is said that the Now Zealander first learned it from immigrants.

Nothing in the anatomical structure of the potato, nor in the physiology of its functions, gives the least countenance to the notion. Its analogy is not found in nature. The miserable and barbarous device neither saves material nor increases production, but, on the contrary, wastes the one and diminishes the other. It blights the vital stamina and transmits imperfect organization and abnormal conditions, ultimating in deformity, disease, and premature decay.

Potato-cutting for seed is really seed-mutilating. In effect it is the rot inoculation. To dissever the 
head from the body of the potato, hermaphrodite though it may seemingly be, is separating the procreative or reproductive organs from the body, or from the greater part of it, so that the source of sustenance is reduced to one-half, or even onefourth, of what is required, and what nature intended and provided. To plant such gelded nips dissevered from the bodily attachment not only debilitates the product, but hazards its very existence.

Did the germ-cut method of planting increase the yield of the potato economically, it would do so with grain and other seeds, fruits and roots. Each single potato, and each single grain of wheat or corn, is a perfect organism ; and just in the ratio that either is mutilated, its generative powers are weakened and its progeny deteriorated.

"What we sow we shall reap." The planted seed should not only be whole, but it should be sound in body and skin. Some superstitious persons believe that the potato-rot is God-sent, and would find a remedy in prayer! But here, 
as everywhere, prayer without works will prove unavailing. Science has dispelled many libels on God and nature, and the plan of culture here recommended will prove that man, not God, is the author of the potato-rot.

Vivisection outrages both parents and progeny ; and when continued not only from year to year but from generation to generation, cannot fail to deteriorate and in time exhaust the crops.

By renewing the germinative members of organic life from their main body, in dividing the potato into several fragments, or slices, each obtains but a moiety of its natural and necessary parental support and mutrient elements; the young shoot is starved; hence the potato blight, or atrophy, which precedes the rot.

Through no channel other than the life-substance of the parent, can the young shoot derive its indispensable food, to nourish the stem until its roots spread and its top or lung expands. Through this channel alone the parent potato imparts its whole life to its offspring; and upon 
its quantity and vigor the health and productiveness of the offspring depend.

When we inquire of the vivisecting farmers why they cut through the structures analogous to the skin, muscle, blood-vessels, and connective tissue in animals, thus utterly dismembering the individuality of the seed, the answer is, it saves seed and causes a more prolific yield.

The fallacy of this opinion will be further exposed under Error 5-its proper place. That the practice of seed-cutting (seed-killing), so contrary to common sense, so tedious and unnatural, so unphysiological and anti-anatomical, should have prevailed so long in enlightened communities, and should, moreover, be so generally practiced without being questioned, is a striking commentary on the nature of inherited prejudice and transmitted error. Is it not time that this proceeding, which threatens the total annihilation of the plum, and the ruin of the plant, should terminate?

[I am satisfied that Dr. McLaurin does not "put 
the case" any too strongly on the subject of mutilating seed-potatoes. But I find the practice almost universal in this vicinity. Indeed, so far as I have been enabled to observe personally, there are no exceptions. I find, too, that many farmers in this truck-farming region, who raise potatoes principally for the Philadelphia market, plant the smallest sizes instead of the largest, probably because they are not saleable, and on inquiry I learn that the general tendency of the potato crop has been for several years to smaller and still smaller sizes. The sizes of the different varieties raised hereabouts do not average more than onefourth the sizes that my father raised in western New York, on new land, between forty and fifty years ago, nor is the quality of these comparable to those.

I can recollect when two large potatoes (in these degenerate potato days they would be considered huge), baked in hot ashes, were a full and linxurious meal, and that too without salt or butter. To think of them is, in the language of Ossian, 
"Like the memory of joys that are past ; pleasant yet mournful to the soul." The best potatoes I can find now are flat and insipid compared with those I once feasted on, and desired notbing better. And the same is true of such apples as I can purchase now, and such as I ate from my father's orchard, when a child. Both crops are sadly degenerated, and nothing but hygienic agriculture will ever renovate them.

In looking over the latest publications of the seedsmen and agricultural journals, I do not find any one objecting to the seed-cutting of potatoes, but most of them recommend it. One of the largest dealers in Philadelphia, Robert Buist, jr., in his "Almanac and Garden Manual" for 1872, recommends the selection of large and good potatoes for seed, but recommends cutting them into four or six pieces. He says, "Many cultivators in this vicinity select good formed tubers and plant them whole; this may be an advantage should the season prove to be very dry, but we look upon it as a great waste of seed, as the product 
from such a crop is no better than that grown from well-formed tubers cut into sets."

The difference may not be appreciable to a careless observer in a single season; but if there is any virtue in the laws of organic life, the practice cannot be otherwise than most pernicious. Is not the admission that whole tubers will do better than mutilated ones, presumptive evidence that there are vital relations between all parts of the seed that cannot be interrupted without injury? If the whole parent-body of the potato is necessary in a dry season, it may be useful in any season. Vitality itself is the best possible protection against drought or wet, heat or cold.R. T. T.]

\section{REMEDY 3.}

"Cease to do evil." Never touch the seedpotato with a knife. Do not mar, mangle, bruise, nor mutilate it in any manner. Drop it into the ground whole and sound. 
Although the magnitude of the evil resulting from imperfect seed is very well seen at its present stage, yet until the maximum health of the potato is attained by the adoption of the plan herein recommended, the full advantages of a good article of food, such as the potato in its highest perfection is capable of affording, cannot be fully realized or adequately appreciated.

When potatoes cultivated in both the wrong and the right ways are seen growing side by side in different fields, the time, labor, and product of each method can be calculated and compared, and then the extent of the present evil can be better understood.

I must here caution the reader against a possible source of miscalculation. Should his neighbor continue to plant and cultivate in the ordinary manner while he is trying the new method, the diseased potatoes of his neighbor may infect his more or less in the bloom - when the pollen blows.

Experimental tests, however, without due 
regard to all the influencing circumstances, may only lead to self-deception. If any one particular, however unimportant it may seem, is disregarded or overlooked, the whole experiment fails.

To test the matter in the best possible manner, after plowing the ground, take the requisite number of laborers, and plant one day on the new plan and then one day on the old plan, in both cases carefully measuring the potatoes planted and the time expended. In the case of seed-cutting, time should of course be reckoned from the commencement of the cutting process; and the potatoes should be measured before cutting, as a bushel of cuts and a bushel uncut differ very materially. Therefore measure a given number of bushels; cut one half of them and plant the pieces, reckoning the time spent in cutting as a part of the day's work. Plant the other half whole; and then the product of both, whin dug, will show the value of each method, so far as the labor of planting is concerned, and their respective values by contrast.

The extent of ground occupied by each should 


\section{The Potato Book.}

be taken into the account. The time at which the blight appears in either ; its extent and virulence ; the quality of the potato - its size, solidity, dryness, and flavor, are also factors to go into the general estimate.

In all the processes and stages of cultivation, in order to have a fair and conclusive experiment, the common method and the one now proposed must be strictly followed; and if the respective products are kept separately, and the two processes repeated yearly, the value of each, or the demerits of the one and the merits of the other, will in due time be conclusively demonstrated; for the new and natural method will gradually and constantly gain on the other, both in the productiveness of the crop in proportion to the labor expended, and in its quality. 


\section{ERROR 4. \\ DWARE PIANTING.}

Another most pernicious error is that of selling or eating the largest and best potatoes and selecting the smaller, poorer, bruised, and scabious ones for seed. If a farmer should apply such a principle to the raising of domestic animals, he would most certainly be suspected of idiocy or madness. Yet the principle is precisely the same in both cases. Nor does the farmer ever think of abusing any seed or root in this manner except that of the unfortunate potato.

The author has never maimed nor cut potatoes for planting; nor has he during the past ten years planted them otherwise than according to the plan herein recommended. He has never had any appearance of disease among them.

The attempt to raise the greatest possible quantity of potatoes per acre by means of strong manuring, engenders and perpetuates disease, and unless abandoned, will prevent all attempts at 
cure. One might as well undertake to raise the greatest possible number of calves from one cow's milk or one acre of grass.

[The subject of manures or fertilizers is one of immense importance, and, in my opinion, before agriculture can become hygienic and placed on a truely scientific basis, the current methods of fertilizing all plants which produce food for human beings must be not only reformed but revolutionized. As water, ammonia, carbonic acid and a few earthy and saline matters constitute the food of plants, and as those are all constituents of the mineral kingdom, it is certainly a roundabout and expensive as well as a filthy and troublesome business to keep animals. for the sake of manuring the soil. It is a common remark that cattle, horses, sheep and hogs, are necessary, if not to work or to be eaten, to supply fertilizers by converting the products of the vegetable kingdom into manure. There is no science and little intelligence manifested in this notion, in view of 
the fact that the whole vegetable kingdom feeds on inorganic or chemical elements, while no animal can produce a particle of food of any kind, but merely subsists on what is formed in the processes of vegetable growth.

Abundant experience has shown that the most effectual method for renovating old worn out or badly-tilled soils is to grow clover or any similar crop, and plow it in. Any vegetable matter of any kind, allowed to decay and decompose, becomes a natural and wholesome fertilizer. But fertilizers can be obtained directly from the mineral kingdom, whenever necessary, more economically and of better quality than animal excretions can furnish.

This subject is well presented in the Scientific American of February 24th, 1872, and as the facts are exceedingly interesting and instructive, I copy the article entire : 
AGRICULTURAL CHEMISTRY AND CHEMICAL MANURES.

The researches of that veteran chemist, Baron Liebig, and others, in the analysis of soils and the use of artificial manures, did not result in such extensive progress in agriculture as was anticipated. As the effort to apply the knowledge gained by these researches was made throughout the world by intelligent agriculturists, it became evident that there was still some lack in agricultural chemistry, somé mysterious circumstance, relation or element, that defeated this endeavor. As a consequence, the idea of chemical farming became a thing to be ridiculed, and fell into an ill repute which still attends it. The prejudice thus created will for a long time impede progress; but there cannot be a doubt that the missing link, which, if found in Liebig's researches, would have resulted in success instead of failure, has at last been discovered.

In the light of this revelation, the cause of the 
failure to apply chemical principles to agriculture is plain. We find it fully explained in the lectures of M. Ville, a translation of which, as delivered at the experimental farm of Vincennes, France, now lies before us.* These lectures are, we believe, the most important contribution to agricultural science that has appeared during the last half century. In our review of them, which we shall not attempt to make exhaustive, we shall extract some passages which will give a glimpse of their character to such as have not read them. In the third lecture, M. Ville remarks :

A priori, one would think that a chemical analysis which has been pushed so far in our day, and whose methods have acquired at the same time so much delicacy and certainty, ought at least to give us a means of estimating with certainty the richness of the soil, and so guiding

* Chemical Manures. Agricultural Lectures, delivered at the experimental farm at Vincennes, by George Ville. Translated by Miss E. L. Howard. Third Edition. Atlanta, Ga. : Plantation Publishing Co. 
us in the choice of the manure best suited to its nature. There is none, however, and I defy the most skilful chemist to say in advance what will be the return from earth submitted to him, and what manures are most appropriate.

A few words will explain the reason why chemistry is powerless to furnish us with these indications : you must recall the distinctions we have drawn between the different elements of which the soil is composed.

Let us suppose a soil containing both quartz, sand and felspar sand among its mechanical elements. For vegetation these two sands are equivalent, althongh the first is from silica and nothing but silica, while the second is a silicate based upon lime, potash and soda, besides containing phosphate of lime in very feeble but appreciable quantities.

Here, then, are two bodies whose composition, in spite of similitude of exterior, have no analogy ; and which, however, are equivalent in an agricultural point of view, because, the felspar being 
insoluble in water, its rôle in regard to vegetation descends to that of the quartz sand, that is to say, to a simple mechanical element. But for the chemist, there are no insoluble bodies, so he confounds in one whole the potash, lime and phosphate of lime that the felspar sand contains, though they are of no use in vegetation, with the products of the same nature which we have ranged under the class of active assimilable elements. Thus is explained the insufficiency of the signs with which chemistry can furnish us.

In order to understand fully the meaning of this quotation, it is necessary to say that $\mathbf{M}$. Ville includes all the essential constituents of soil in which plants can grow, in the category of fertilizers; but he divides them into two classes, the first of which is azotic or nitrogenous matter, and the second of which includes ten mineral suhstances, only three of which, phosphate of lime, potash, and lime, are so directly connected with the growth of plants that they need occupy the 
attention of the agriculturist in his attempt to restore to soils what has been drawn from them by the growth of crops. The other minerals act mechanically and are hence called mechanical fertilizers ; but M. Ville maintains that they exist naturally in sufficient quantities, and that it is not necessary to provide them. So far as the mere growth of plants is concerned, this is probably correct, but there are doubtless many cases in which it is desirable to add some material not directly concerned in plant growth, for the purpose of modifying stiff soils, or tempering light ones.

The most favorable conditions of soil for plant growth being the presence of azotic matter, phosphate of lime, potash, and lime, M. Ville calls a mixture of these substances "the complete fertilizer." The non-assimilable elements are considered as purely mechanical in their effects.

The following experiments are given to illustrate these facts :

In burnt sand, free from all additions, but 
moistened with distilled water, wheat acquires but a rudimentary development-the straw hardly attains the dimensions of a knitting needle. In this condition, however, vegetation follows its usual course ; the plant blooms, bears grain, but in each head there are but one or two dwarfed, badly formed grains. Thus, without soil, the wheat finds in the water it receives and the carbonic acid of air, aided by the substance of its grain, resources sufficient-sorrowfully, it is true, but at last-to run through the entire cycle of its evolution.

From 22 grains of seed, weighing nearly 18 grains, we obtain 108 grains of harvest. Add the ten minerals (phosphorus, sulphur, chlorine, silicium, calcium, magnesium, potassium, sodium, iron and manganese) to the sand, excluding the azotic matter, and the result is but little more.

Under these new conditions, the wheat is a little more developed than in the preceding case, but the harvest is still more feeble; it reaches 144 grains. Suppress the minerals and add only 
azotic matter to the sand; the growth will still be mean and stunted, but the harvest will slightly increase, as it reaches 162 grains. Let us follow the changes. In pure burnt sand, 108 grains; with minerals without azotic matter, 144 grains; with azotic matter alone, 162 grains.

In this last case, a new system is shown. As long as we operate only with minerals, the plants are diseased, the leaves show a yellowish-green color. As soon as we add azotic matter to the sand the leaves change their color, becoming a dark green. It seems as if vegetation would take its usual course, but the appearances are deceitful; the harvest is still feeble.

Let us attempt a third experiment, which will, in a measure, be a synthesis of the three preceding. Unite azotic matter and the minerals in the burnt sand. This time you will be tempted to believe in the intervention of a magician, the phenomenon so far surpasses those preceding it. Just now the growth was languishing, doubtful, diseased; now the plants shoot up as soon as they break the 
ground; the leaves are a beautiful green; the straight, firm stalk ends in a head filled with good grain; the harvest reaches from 396 to 450 grains.

You see, gentlemen, relying on experience, which is our guide by choice, we have succeeded in artificially producing vegetation to the exclusion of manures and all unknown substances.

You will acknowledge that this is an important and fundamental point. No more mystery, no undetermined power; some chemical products of a known purity, distilled water perfectly pure in itself, one seed as a starting point, and the result, a harvest comparable in all points to the best obtained in good earth.

We are, therefore, justified in saying that the problem of vegetation here receives its solution, for we have not only defined the conditions necessary to the production of vegetation, but the degree of importance of each of the concurring agents.

Azotic matter in its decomposition furnishes 
ammonia, and nitrates; and the clay constitutes a receptable which holds and gives out gradually as may be required these important ingredients. M. Ville divides plants into two classes, according as they draw their nitrogen from the air or the soil. Thus wheat is a type of plants which prefer their nitrogen in the form of salts of ammonia, and take it from the soil. Beets prefer it in the form of nitrate, and take it from the soil. Peas and the other leguminous plants prefer to take it as a gas from the air. The consequence of this distinction is that plants which take nitrogen from the air will flourish in a soil containing only the other elements of the complete fertilizer, namely, phosphate of lime, potash, and lime. Therefore, by planting in a soil one of each of the two classes of plants, it is possible to tell whether the soil contains the azotic and mineral matters or not. Thus, if peas and wheat be planted in the same soil, and the peas yield well while wheat yields little, the land has the mineral elements but lacks the azotic or nitrogenous matters. 
At Vincennes, previous to the fertilization of the soil, land produced nothing, and hence ras proved deficient in all the elements of the complete fertilizer, by the addition of which it has been made extremely productive.

As chemical analysis of soils fails for reasons above stated, the richness of the soil is determined as follows :

Suppose you institute seven cultures of the same plant-it may be of the beet, or wheat, as you will.

To the first give the complete fertilizer ; to the second, the same fertilizer, excluding azotic matter; to the third, the complete fertilizer deprived of phosphate of lime; to the fourth, the complete fertilizer less the potash; to the fifth, less the lime; to the sixth, less all the minerals-that is to say, reduced to the azotic matter; the seventh not having received any manure.

It is very evident that if, in the complete fertilizer, the effect proper to each component is manifest but as it is associated with three others, the comparison of the returns obtained from the seven 
strips of the little field ought to indicate what the soil contains and in what it is wanting.

In this system of investigation, the culture with the complete fertilizer becomes, in a measure, the invariable standard of comparison to which are referred the returns of the other strips of ground; and, according as they approach or recede, we conclude that the earth contains or does not contain the element which has been voluntarily excluded from the fertilizer.

To put the value of this method beyond doubt, M. Ville reports the results given under three different conditions.

At the experimental farm at Vincennes were obtained, in 1864, the following proportional returns from wheat :

With the complete fertilizer........... 5644

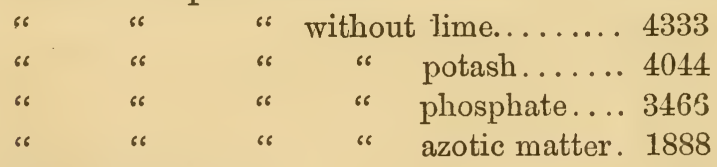

Without any fertilizer ............. 1588

The conclusion is evident. At Vincennes, the 
complete fertilizer was necessary : the azotic matter was most deficient.

An eminent agriculturist of the department of the Somme furnished a second example, which is upon the beet :

With the complete fertilizer.......... 4504

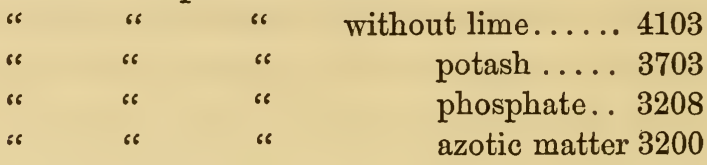

Without any fertilizer............... 2202

You see here, also, the earth is wanting in azotic matter, and, to put it under high culture, we must have recourse to the complete fertilizer.

The third example is from a culture of sugar cane, instituted by the Hon. M. de Zebrun, of Guadaloupe, a former delegate from that colony :

With the complete fertilizer......... 50666

$\begin{array}{lll}66 & 66 & 66 \\ 66 & 66 & 66 \\ 66 & 66 & 66 \\ 66 & 66 & 66\end{array}$

$$
\begin{array}{r}
\text { without lime .... } 44444 \\
\text { potash... } 32111 \\
\text { phosphate } 13333 \\
\text { azote.... } 49777
\end{array}
$$

Without any fertilizer.............. 2666 


\section{The Potato Book.}

If I add that sugar cane particularly draws its azote from the air, you will conclude that the soil is particularly wanting in potash and phosphate of lime.

Here are, then, two methods of knowing the richness in the land. The first is founded on the culture of two different plants without any fertilizer, and the second, on the culture of the same plant with five different fertilizers. These two applications of the same principle lead to the same results, and verify and complete each other.

I need not add, that for each of these trials to have its full signification, the earth must not be used until the effect of each fertilizer has been spent.

By the aid of our experiments in burnt sand, and with only chemical products, we have realized a theoretic scale of culture whose progressive returns have shown us the laws which regulate vegetable productions. By the light of the collection of ideas, we were enabled to conceive and to realize practical processes of analysis accessible 
to all, whose testimony is of almost absolute certainty, and by means of which we can always say what a land contains, what it needs, and can con-, sequently determine the nature of the agents to which we must have recourse to fertilize it.

In subsequent lectures, M. Ville gives tabulated statements of results from the use of what are ordinarily called chemical fertilizers, that is, such as are not directly of organic origin. These statements indicate that the chemistry of plant-growth is destined to pass from under the odium of previous failures, and take its place in the sciences as a splendid collection of established facts, which will inaugurate a new era in agriculture.

We cannot extend our remarks and quotations further, but we will say that we have rarely examined a work more replete with interest, or perused a record of experiments in which the true scientific method has been more closely followed. R. T. T.] 


\section{REMEDY 4.}

Reserve your best and largest potatoes for seed, just as you would act in the business of raising animals; or as you would do were the seed anything else but that of the potato; for that which is not fit for eating or selling is certainly not fit for planting.

Potatoes will produce more abundantly by weight, in an equal ground or air space, if the number is smaller and the size larger, than if the reverse be the case. Dividing half a dozen large potatoes into two or three times as many small ones, adds nothing to the quantity, while it impairs the quality. A potato of one pound weight will produce a greater yield of potatoes than it will if it is divided into fragments, or cut into what are called "Seed sets," in an equal area of land, provided the proper conditions of culture are observed; hence the labor expended in cutting is worse than wasted, for it both damages the quality and diminishes the quantity. 
It is no exaggeration of the truth to say that a bushel of large potatoes can be planted sooner than half a peck of cuttings. The labor of planting, therefore, is greatly lessened when the planting is done normally. By this method the potato will increase in size from year to year, while by dwarf-planting the constant tendency is to diminution in size, imperfection in quality, disease, and decay.

\section{ERROR 5.}

\section{OROWDED PIANTING.}

Insufficient allowance of space for potatoes to grow in, as well as stinted size of seed, is the rule with farmers, the exceptions being very few. But the error is a very grave one, and the injurious consequences are second only to seed-cutting.

Although there is a continued circulation and admixture of properties derived from the earth and from the air, and a constant reciprocal opera- 
tion or interchange of elements through and between the stem and the roots, yet in the growth of a potato it receives much the larger proportion of its nutritive material from the atmosphere ; consequently it is not so much for want of earth-room as for want of air-space that the potato suffers when planted after the ordinary fashion.

The potato, as well as an animal, or a human being, must have sufficient breathing room, or it cannot maintain its normal condition, nor produce sound structures. Its foliage constitutes its lungs, and with its stem or stalk, its respiratory apparatus; hence a given space, so that it can have the exclusive use of sufficient atmosphere, is absclutely necessary to vigorous growth. There must, therefore, be proper distances between the plants.

In vain will potatoes of ample size and unblemished quality be planted, unless they are placed far enough apart to afford the indispensable room for healthful respiration. The space between the planted potatoes should always 
correspond with their size - the larger the potatoes the further apart.

Much deception, in judging of the propriety of planting whole potatoes, is attributable to the miserly allowance of room. So long as whole potatoes, however large and sound they may be, are crowded together in planting, the farmer will never be able to discover the intrinsic difference between whole and fragmentary seed; for size of seed without sufficient room for it to grow in, and ample space without the proper size of the seed, are equally detrimental; and either may be as bad as cut-seed.

It is just because sufficient space between the seed is not allowed, when whole potatoes are planted, that many persons suppose that the planting of cuttings will be economical and save a part of the seed in the production of a given crop in bushels. Indeed, some persons think that they have proved the cuttings to be more prolific than whole potatoes. It may be true that cuttings with ample space will produce a larger 
crop than whole potatoes can with less than half the space required; for it is possible so to crowd them as to render any considerable yield impossible.

\section{REMEDY 5.}

Plant the potatoes at uniform distances apart, according to size. From three and a-half to four feet is the general rule. Three feet may suffice for the first year ; three and a-half will be needed the second year, and possibly four feet the third year, according to the increase of size from year to year. It is quite possible, and, indeed, probable, that the discovery or production of new and larger kinds of potatoes, with unusual expansion of stem, would render a space of more than four feet beneficial.

The seed potatoes (the largest size, and perfectly sound) should be carefully dropped. They should be unsprouted; and if properly preserved for the purpose of planting, there will be no 
sprouting until they are placed in the gromad. If permitted to germinate before being planted, they will be more or less damaged; nor will the progeny be so vital or prolific. If the sprouts are long, or have been broken off, the potatoes should never be planted.

No potato of less than half a pound in weight should be planted; if it is, the loss to the planter is much greater than the gain can possibly beespecially if results beyond a single season are calculated. The larger the potato, if not excessive, the better, provided that sufficient space is allowed for it to grow in.

The law of propagating size from size holds good alike for vegetables and animals. Size and space should always be carefully adapted to each other, for, as already remarked, one is comparatively useless without the other. $\mathrm{He}$ who sows bountifully in relation to both size and space, will reap bountifully. 


\author{
The Potato Book.
}

\title{
ERROR 6.
}

\section{DEEP PIANTING.}

Burying the seed potatoes as though they were dead matter, into the cold bottom of a deep furrow, where the undrained moisture settles, and the vivifying heat of the sun never penetrates efficiently, is another egregious blunder. They should, on the contrary, be placed on the surface of the ground, the sod being turned over them.

The ordinary deep planting retards growth, delays maturity, and enfeebles the whole plant. Potatoes so treated cannot have the dryness, firmness, sweetness, nor the size nor yield of th ose that are properly managed. Such planting also predisposes them to disease.

[I am inclined to the opinion that surface planting may be a very important matter for other crops as well as potatoes. The soil in this vicinity is dry and sandy; corn does well, except in unusually dry seasons, and melons do splen- 
didly except in wet seasons. Last season I planted water-melons between the rows of grape vines which had been planted two years before. They grew well until July, and promised an abundant yield. But the month of July was unusually rainy, and when the melons were nearly grown the vines began to perish, and soon after every melon rotted. One of my neighbors

- had several acres, of as thrifty and promising a crop as I ever saw. In ten days more they should have been ready for market. They had all attained the full average size. But several rainy days spread a blight over the whole field. The melons seemed pervaded with gangrene. They became discolored, rapidly softened and rotted, and the vines turned dark, and soon withered. Not one melon ripened. Perhaps if the seeds had been planted on the surface after the manner that Dr. McLaurin recommends for potato planting, or on ridges a little elevated above the general level, the rains would not have destroyed them.R. T. T.] 


\section{REMEDY 6.}

Run a furrow with a double-moulded plow, alongside of the edge of the upturned sod; not in the furrow, but on the surface, drop your large potatoes, three and a half to four feet apart, as already explained. Your return trip will cover the seed, and, at the same time, turn over a new sod ready for another row of potatoes to be dropped, and so on until the whole field is planted. The quantity that can be planted in one day by this new method is double or triple that which can be planted in the old way, thus accomplishing another great saving of labor.

The calibre of the plow should be such, if possible, as to be capable of opening a furrow twenty-one inches or two feet wide : that is, ten and a half or twelve inches on each side, so as to equalize the distance of the sets apart, crosswise as well as lengthwise.

This method of planting is admirably adapted to prairie or fallow land; for the tougher and 
more grassy the sod the better; when overspread with a thin coat of some fertilizer (mineral is best) and the sod turned over, it resembles a sandwich, or two pieces of buttered bread turned butter to butter. The surface of one sod overlapping the surface of the other, brings grass to grass, which, decaying makes a covering of rich manure in which the seed potatoes are embedded.

When the potatoes are dug, this sod, if tough, and only partly decomposed, turns back into its original portion, exposing the potatoes to view, huddled together like turkey's eggs in a nest, and almost as clean.

If, on the same field, potatoes are planted two successive years, this plan will allow the alternate two feet of land left unplowed the first year, to be plowed the second year, and so alternating. The drill or ridge one jear may be where the furrow was the preceding year.

Should subsoiling be deemed necessary at weeding time, run through all the drills or ridges a double-mould plow, capable of turning up a furrow 
of about one foot in width only; that is, six or seven inches on either side; and in two successive years the field will be sufficiently subsoiled. In this manner the whole farm may be subsoiled by planting potatoes two years in succession in one field, and then changing to another. And nothing could better vitalize the soil, so to speak, than by exposing it to solar, atmospheric and electrical influences in this manner; and no better method could be devised to renovate and render productive old worn out lands-rendered so by the unhygienic, unnatural and destructive method of farming in vogue.

Other crops may be managed in a similar manner. Indian corn, where this cereal is indigenous, may be plowed and planted in all respects the same as potatoes, except that the drills or ridges may not be so wide. The seed corn may also, if preferred, be dropped after the plow instead of before it. But it should not be thrown together in groups, as is customary; but the kernels should be planted singly, at distances of about twelve inches 
apart. Corn can be sown in this manner by machinery.

Potatoes may also be planted after the plow, and sometimes it may be the better way.

\section{ERROR $\%$}

\section{EXOESSIVE OOVERING.}

Smothering the potato by over-covering it is also one of the evils of the common method of planting it. Heaping too much earth on the seed, even when planted on the surface of the ground, instead of in the furrow, hinders a speedy development of the shoot, prevents a rapid growth, retards maturity, impairs the quality, and diminishes the yield. It is also among the predisposing causes of disease. 


\section{REMEDY $\%$.}

Two or three inches of earth, and sometimes even less, according to the moisture or dryness of the soil, are quite sufficient. The more moist the ground is, the less covering the potatoes should have : the danger is ever on the side of excess in lands so constituted as to retain a large amount of moisture.

The principal objects of covering the potatoes with earth are, to obtain and maintain both heat and moisture in due proportion, without exposing the seed to light and air. If buried too deep, the moisture and cold will prevail ; while, if too near the surface, the moisture may be deficient and the heat excessive.

Freedom from grass and weeds is ever an indispensable requisite to a perfect crop. Potatoes should never be planted under the shade of trees or high fences. Nothing should obstruct the free play, upon the growing plant, of air and light, of winds, sun, moon, and stars. 
To the cultivation of the sweet-potato this method is equally applicable in all respects, both in producing the best possible crop, and in preventing and curing its diseases.

[The remarks of an eminent scientist on the subject of the influence of the sun and light in the process of germination, are pertinent here, and confirmatory of Dr. McLaurin's views. I cannot, however, regard the influence of the sun as "chemical" action. Chemical action and vital action are antagonistic ideas. There is no chemistry in living structures. Chemical action means the combination and separation of elements -nothing more, nothing less. Vital action is transformation and disintegration-very different processes. Chemical action arranges primary atoms or elements into combinations which are capable of decomposition, by which the primary atoms or simple elements are restored. Nothing like this occurs in the domain of organic life. Living organism, by the various nutritive processes, 
transforms food into tissues, structures, and organs. These cannot be separated or decomposed chemically, nor can chemical analysis ever tell us what their composition is, for the reason that vitality ends before chemistry begins. They are only retro-transformed (disintegrated) into the various excretions. Chemistry will never solve the problems of life, although it may aid us in understanding the substances which living organisms use in the construction and replenishment of their bodies, and help us to provide the requisite conditions for the proper performance of all vital functions. Our author, however, expresses the current opinion on this subject. He says :

"Upon the chemical influence of the sun's rays depends the germination of seeds as well as the growth of the plants. We bury the seed in the ground and shut it out from the influence of light, but we do not place it beyond the reach of the sun's actinic influence, for that penetrates like heat to the little earthy couch were the embryo plant lies hid, and arouses it into life. Light, or 
the luminiferous rays of the sun, so important to the well being of the plant, is actually inimical to the excitation of vitality in the seed. How singular is this fact! A series of carefully conducted experiments has proved that seeds will not germinate in light, although supplied with heat and moisture, when the actinic rays are cut off. Deprived of the luminous rays with the actinic in full force, they spring into life with great rapidity. Seeds sown upon the surface of the earth will scarcely germinate, as soil cultivators very well know, and, on the other hand, seeds buried so deep that the actinic rays cannot reach them will certainly perish. The planting of seeds, so as to secure the proper distance below the surface, is a most important point in husbandry, as it has much to do with the early starting of the plant and the success of the crops."-R. T. T.] 


\section{DIGGING POTATOES.}

The manner of digging potatoes must be left to the machinery of inventive genius : but the time for digging must́ be determined by physiological laws, demonstrated by actual experiment.

- [Twenty or thirty potato-diggers have been invented and patented, some of which are more or less useful. Most of them, however, only throw the tubers out of the ground, leaving them to be picked up by hand, as usual. One or two hare been constructed and used to some extent, which gather as well as dig them. But they are too heavy and expensive for general use, if indeed they are profitable at all. But I believe the desiderata in machinery is at last attained, in a new "Potato Digger and Gatherer," invented principally by Mr. G. N. Kilbourne. A model was on exhibition at the late fair of the American Institute, in New 
York, and elicited universal approbation. A working model has also been tested satisfactorily. This machine is about the size and weight of an ordinary one horse cart, and can be easily operated with a span of horses and driver. It takes the potatoes from the ground, raises and sifts them on a revolving elevator, and deposits them in a box under the rear part of the machine. It is provided with an adjustable plow, which can be elevated or depressed at will, according to the depth of the hills, and a lever, by which the rider and driver can empty the box when filled. It has also a circular rake or harrow in front, which removes the vines. It will operate equally well with Irish or sweet potatoes. The machine will be in market in time for the next potato-digging season, and will not cost to exceed one hundred dollars; and as one machine will do the digging for a dozen farmers (unless their potato fields are immense), the expense can be no objection. -R. T. T.]

From planting to cooking, and in all processes 
between and inclusive, potatoes are unquestionably the most abused things ever cultivated for human use ; and in the long catalogue of errors peculiar to this excellent esculent, one of the most outrageous is, neglecting to harvest them as soon as they are ripe. No other crop was ever maltreated in this way. When any other crop is fully matured, the farmer secures it at once, lest it wastes and decays. But potatoes, being out of sight, are out of mind until a convenient season. When the farmer can find nothing else to do he digs them, and then perhaps complains of them for being of bad character. Any other crop would be as bad or worse if treated in a similar manner.

Potatoes are not unfrequently left in the ground several weeks after being ripe, as though they were dead stones and undamageable, instead of living, perishable organisms, subject to all the conditions, changes, transformations, and diseases that pertain to all vital structures.

It is seldom that potatoes are not more or less damaged by neglect to harvest at the proper 
time, or by improper management in harvesting, however well they may have been raised and matured.

When the tops of potato plants wither, the tubers are ripe, and, like other crops, will be injured if not at once gathered and taken care of. If allowed to be once soaked in the ground by a severe or prolonged rain, after ripening, they lose irreparably some degree of their sweet flavor, and some portion of their nutrient properties. Nor are they so sound and vital for seed-potatoes; and every rain augments the damage, rendering them both less palatable and less wholesome.

What farmer can be ignorant of the fact that the potatoes he digs in November and December are less dry and sweet than those he ate from the same field in September and October previously?

Potatoes should not be exposed to the air, sun, or wind to dry them, as is customary, after being dug. If moist or dirty when taken from the ground, cleaning and drying does not protect them, but the reverse. Every petato that becomes 
uncovered before it is ripe, or which protrudes above its earthy covering, soon becomes blighted in the exposed part-a fact which proves that it is defenceless against aerial elements, and its need, when dug, of immediate protection.

[Dr. McLaurin's remarks on this subject are corroborated by Mr. Compton in his Prize Essay, previously alluded to, in the following strong language: "Potatoes should be picked up as soon and as fast as dug; and immediately covered with straw or other material to protect them from the light. A few hours' strong sunshine will ruin the best potato ever grown. Light changes the natural color to green, and renders the potato so bitter and unpalatable as to be wholly unfit to eat." Those who will take pains to observe the truck farmers for the New York and Philadelphia markets, in the potato-digging season, will learn that a practice obtains the very opposite of that insisted on by ${ }^{\circ} \mathrm{Dr}$. McLaurin and Mr. Compton. As a rule, the potatoes, after being dug, are exposed several hours to the sun, and in 
some cases they are left on the ground during the night. After being dried, and more or less injuriously heated, and to some extent blighted, they are gathered into baskets. The next day, or possibly several days thereafter, they are sent to the cities. They are constantly exposed in transitu to light, and often to sunshine. Sometimes they are piled up in huge heaps near the boiler of the steamer which carries them to town, where the blighting, if not rotting process already engendered, is further aggravated. In the markets, and at the groceries, they are continually exposed to light, and not unfrequently they remain for hours in barrels, baskets, or smaller measures, exposed to the hot rays of a midsummer's sun. When those potatoes reach the consumer they are very far from being potatoes as they should be. They have lost more than one half of their nutritive value, and more than that proportion of natural flavor. No wonder potatoes have come to be so generally regarded as a desirable accompaniment of other food, rather than 
as food themselves. No wonder that such immense quantities of grease, butter, and salt, are required to render them palatable. I doubt if one person in a hundred knows what the natural taste of a potato really is. $-\mathrm{R}$. T. T.]

To secure and preserve potatoes sound, fresh, and unsprouted, the one great principle of thorough protection from atmospheric influences must be rigidly maintained. This principle applies alike to sun, light, heat, air, rain, and frost. They must also be kept by themselves in closed cellars or bins, or in an underground pit or root-house, with a top-hatch to receive them, and a small side door underneath to admit of their being taken out. This door must be kept constantly closed except when the potatoes are being put in or taken out.

A thermometer placed within the bin for ten minutes will show the temperature, which should not be allowed to fall below thirty-three degrees Fahrenheit, nor to rise above fifty degrees. The more constantly the temperature is maintained at 
about forty degrees the better. In this manner they may be kept sound and unsprouted through the whole summer season.

Cabbages, carrots, turnips, beets, onions, and parsnips grow with their bodies partially exposed to air and light, and when ripe, cannot bear entire seclusion from air without rotting. Potato tops grows similarly, and no vine is more tender, nor more easily affected by frost and mildew. Equally is the tuber affected throngh its medium, the top, until it ceases growing, when the entire exclusion of all atmospheric elements becomes essential to its proper preservation. Like the habitation of the blind mole whose normal state is total darkness, the cellar, bin-pit, or earth-covered and airless cave, is the natural home of the potato. Those who expose their potatoes unnecessarily to air, light, and sunshine, know little of the injurious consequences. No food can long be exposed to oxygen without more or less injury; but the potato, both because of its constitutional nature 
and its underground habitat, is remarkably susceptible to its deleterious influence.

Some retail dealers, with the best intentions, wash their potatoes, besides exposing them constantly to the air, a practice damaging to their quality and conducive to decay. But as potatoes so treated and exposed, are usually soon disposed of, the dealer does not notice the difference in quality between them and those which have been properly kept and protected.

If some one would try the experiment of cooking some potatoes which have been exposed to air and light for a month or two in a huckster's shop, and compare them with others taken immediately from the cellar to the cook, he would then be prepared to appreciate the difference between a good and a bad article of food.

But, bad as is the influence of atmospheric air on the quality of the potato, that of the sun is still worse. Potatoes which have been long exposed to sunshine are actually dangerous to health, and ohould never be planted, eaten, bought, nor sold. 
Nor should long, scraggy, broken or sprouted potatoes be eaten or planted.

Hucksters may bin a barrel of potatoes for a short time, except where they are liable to freeze, for transportation or temporary convenience; but even then they should cover them, or place them in the cellar during the night. In transporting them long distances the same rules for protecting them should be applied, so far as possible under the circumstances.

\section{COOIIING POTATOES.}

With the majority, perhaps nine-tenths of mankind, who "live to eat" instead of " eating to live," the question is not how to cook potatoes in order to obtain from them the best nutrition-the best material for blood-making, bone-making, muscle-making, nerve-making, and brain-makingbut how to cook them so as to gratify perverted instincts and depraved appetences, or how to 
follow most slavishly the prevailing fashion. Only the true and practical hygienist, who cultivates the potato and preserves it in accordance with the laws of its organization, and then cooks it according to hygienic rules, can know its real value as an article of food.

Of the woman who steeped her first pound of imported tea, it is said that she rejected the juice, and to make up for the lost strength and flavor, served up the sapless and insipid leaves with butter, pepper and salt. With equal wonder will it some time in the future be told that, ever since the importation of the potato into Europe, it has been treated by most people in a similar manner.

Although tea and potatoes differ very greatly in kind-one being innutritious if not poisonous, and the other nutritive and wholesome-they are alike in organic conditions and elementary arrangements. Boiling out the juice of potatoes, and its cortained elements-nutritive matters held in solution-and throwing away one-third part (more or less) of their alimentary principle, is as 
absurd as to steep the tea, throw away the water, and eat the leaves. The materials which are soluble in hot water, and which are removed by the process of boiling, are as essential to perfect nutrition as are the more solid portions; and no condiments nor seasoning can substitute that which has been thus lost.

When apples are boiled for sauce, the juice is never rejected. Why then throw away the juice of boiled or mashed potatoes? The one being a fruit and the other a root does not alter the principle in the least. The juice of all things that grow, and are proper articles for animal or human sustenance, is as much food as are the solid constituents. It is the product as a whole that constitutes pure and perfect food, no one element, whether organized into structure, or floating in solution (a constituent of its vital fluid) can be abstracted without lessening the nutritive value of the remaining portion. Indeed, the remainder is not food at all in the physiological sense.

During the great famines which have occurred in 
Ireland no less than four times in consequence of the failure of the potato crop, the deaths of starvation were more numerous because the potatoes, which constituted sometimes the whole dietary material, had their nourishing properties impaired by boiling. Paul warned Timothy against old wives' fables. That potato-juice is poisonous, is among the fables that may excuse its rejection, without rendering the practice of rejecting it any the less injurious.

The excellence of Irish and Scotch potato-soups is attributable to the fact that none of the natural ingredients, solid or liquid, are wasted in cooking. No more wholesome food exists than potatoes baked, steamed, or boiled, provided that when boiled the juice be all saved (and not too much condensed) and mashed with them.

[The laudation bestowed upon the potato as food, and the superior merit claimed for this method of cooking it, may seem extravagant to those who do not appreciate the principle involved. 
But they have only to try the experiment fairly to be convinced that Dr. McLaurin does not exaggerate in this matter. I have myself many times cooked potatoes in their own fluid, and I know they are always sweeter, dryer, richer, and more satisfactory to the stomach, than when cooked by any other method. I have made many a whole meal of them and nothing else; and if I were to judge from personal experience and observation, I should say their nutritive value was more than doubled. And this, in a country consuming $150,000,000$ of bushels as food annually, is no small item on the score of economy alone. But, on the score of health, its importance is still greater. This one recipe alone is of more value to the human race than all the lectures and books Professor Blot has ever spoken or written.R. T. T.] 


\section{IIXGIFINIO COOIXING.}

Potatoes may be cooked in many ways healthfully, in accordance with the one principle above indicated. Whether boiled, baked, or steamed, no constituent originally contained in them should be extracted and wasted : nor should it be destroyed, dissipated, changed, or lost by overcooking.

One example of proper cooking may serve as a rule for all processes: Wash the potatoes thoroughly, but quickly. The shorter time they are in the water the better. They should be cooked in a tight-lidded, untinned, metal saucepan; and it is better to have the lid of the sauce-pan of the same metal as the vessel. Place this over the fire without water, as for boiling, the fire being an ordinary one.

To ascertain whether they are done, take the vessel off the fire, and quickly raise the lid. If not sufficiently cooked, return the vessel quickly 
to the fire. When done, remove them at once from the vessel.

It is better to have the vessel about two-thirds filled with potatoes; hence the vessel employed should be of a size adapted to the quantity to be cooked. About three-fourths of the bulk and weight of potatoes are water. This quantity of fluid is ample for producing all the steam required to cook them. Steam is hotter than boiling water, cooks the potatoes quickly, and renders them dry, rich, and luscious. Good cooks will neither burn the food nor injure the vessel.

[Potato-soup, made in the manner proposed by Dr. McLaurin, is one of the favorite dishes in my institution for invalids. I never knew a person, sick or well, to dislike it; and the majority are extremely fond of it the first time they taste of it, even when coming from an ordinary hotel or boarding-house dietary, where almost everything is highly seasoned, to simple fare without any seasoning at all.-R. T. T.] 
Steaming vegetables with pealed potatoes mingles the strength and flavor of all, and affords a palatable meal for sound stomachs and normal appetites. But as potatoes are the soonest cooked, they should be removed before the vegotables are done, or else not added until the vegetables have been cooking for a time.

If potatoes are steamed to be mashed, milk may be added to soften them, for those who use milk; but to persons to whom milk is objectionable, gruel, or some juicy liquid, is preferable, as well as more hygienic.

When potatoes are boiled to be mashed, it is important to have the proper quantity of water, as excess or deficiency injures both quality and flavor.

A meal of potatoes may be prepared in a few minutes by peeling them, slicing them very fine, putting them in a frying-pan, covered so as to retain the steam, and placing them over a fire hot enough to cook without burning them. They should be cooked in about ten minutes. 
Steaming potatoes over water, or by the vapor of water, prevents the due abstraction of the water contained in them, which abstraction is absolutely necessary in order to render them rich and savory, as they should be. Each potato has sufficient water to generate the steam necessary for cooking it, and needs no extraneous supply.

Baking potatoes is not excelled by any other method of cooking, when it is properly performed. But the common mode overcooks some parts of them, and burns other parts to cinders, even when they are not further damaged by being greased. To these objections steam-cooking is not liable.

The common practice of frying sliced potatoes in butter or lard, or in grease of any kind, is one of the dietetic abominations that needs only to be mentioned to be condemned. It is among the many causes of dyspeptic stomachs and disordered livers.

A large proportion-indeed, much the greater portion -of nearly all kinds of food are spoiled by the fashionable processes of cooking and modes of 
seasoning, intended to please depraved tastes, pander to morbid stomachs, and imitate fashionable ways. And food which is intrinsically wholesome, palatable, and even delicious to unperverted tastes, may be distasteful and even repulsive to those whose organic instincts and perceptivities have become diseased and abnormal. Such persons will never know the pleasures afforded by pure food and good digestion, until by a persevering use of natural food naturally cooked, and eaten without unnatural admixtures or additions, their appetences are restored to a state of nature. In conclusion, the author adds the beautiful little poem on the next page, lately published, of which Robert Burns is the reputed author. 


\section{TO THE POTATO.}

Guid e'en, my auld acquintance cronie! I'm glad to see thee bloom sae bonie; Of fruits and flowers there is nae monie,

Can match wi thee;

I question much if there be onie, At least to me.

It's now twa months since ye've been wi us, As soon's ye can, come in and see us; Ye'll banish poverty quite frae us, The time ye stay;

And trowth, I hope ye winna lea us, Till Whitsunday.

I'll mak my braw young bouncing wencher Place thee upon a bowl or trencher, Wi floods of milk as deep as stincher,

\section{In case I had it ;}

I'll show thee fairly I'm no fincher,

When once I said it.

Ye're now the poor folks' bread and scon, And hungry meals ye gar stun yon, Frae me, to him wha fills the throne O happy Britain ;

Baith young and auld, man, wife, and wean, Ye had them eatin. 


\section{WORKSON}

\section{HYDROPATHY, OR WATER-CURE.}

PUBLISHED BY

\section{S. R. WELLS, 389 Broadway, N. Y.}

Hydropathic Encyclopedia: a System of Hydropathy and $\mathrm{Hy}$ giene. In 1 large octavo volume. Embracing Outlines of Anatomy -illustrated; Physiology of the Human Body ; Hygienic Agencies, and the Preservation of Health; Dietetics and Hydropathic Cookery ; Theory and Practice of Water-Treatment; Special Pathology and Hydro-Therapeutics, including the Nature, Causes, Symptoms, and Treatment of all Known Diseases; Application of Hydropathy to Midwifery and the Nursery; with nearly 1000 pages, including a Glossary, Table of Contents, and a complete Index. Designed as a Guide to Families and Students, and a Text-Book for Physicians. With 300 engraved illustrations. By R. T. Trall, M.D. $\$ 4.50$.

In the general plan and arrangement of prevailing conceits and whims of the day the work, the wants and necessities of the people have been steadily kcpt in view. Whilst almost every topic of interest in the departments of Anatomy, Physiology, Pathology, Hygiene, and Therapentics is bricfly presented, those of practical ntility are always put prominently forward. The and age are exposed and refuted ; the theories and hypotheses npon which the popular drug-practice is predicated are controverted, and the why and wherefore of their fallacy clearly demonstrated.

It is a rich, comprehensive, and well-arranged encyclopedia.-New York Tribune. Anatomical and Physiological Plates. These Plates were arranged expressly for Lecturers on Health, Physiology, etc., by R. T. Trall, M.D., of the New York Hydropathic College. They are six in number, representing the normal position and life-size of all the internal viscera, magnified illustrations of the organs of the special senses, and a view of the principal nerves, arteries, veins, muscles, etc For popular instruction, for families, schools, and for professional reference, they will be found far superior to any thing of the kind heretofore published, as they are more complete and perfect in artistic design and finish. Price for the set, fully colored, backed, and mounted on rollers, sent by express, not mailable, (net) $\$ 20$.

The Hygienic Hand-Bools: a Practical Guide for the Sick-Room, with Appendix. By R. T. Trall. One vol. 12mo, price $\$ 2$.

A new and carefully-revised edition of $\mid$ should be in the hands of all who would this work has just been issued, which get well and keep well without drugs.

Hydinpathic Family Physioian: a Ready Prescriber and Hygienic Adviser. With Reference to the Nature, Causes, Prevention, and Treatment of Diseases, Accidents, and Casualties of every kind. With a Glossary and copious Index. By Joel Shew, M.D. Illustra ted with nearly 300 engravings. One large volume, intended for use in the family. $12 \mathrm{mo}, 816 \mathrm{pp}$. Muslin, $\$ 4$.

It posseses the most practical utility of $\mid$ the reader an accurate idea of the organizaany of the author's contributions to popu. tion and functions of the human frame.lar medicine, and is well adapted to give $\lambda^{\top} \in w$ York Tribune. 
Water-Cure in Chronic Diseases : an Exposition of the Causes, Progress, and Terminations of various Chronic Diseases of the Digestive Organs, Lungs, Nerves, Limbs, and Skin, and of their Treatment by Water and other Hygienic means. Illustrated with an engraved View of the Nerves of the Lungs, Heart, Stomach, and Bowels. By J. M. Gully, M.D. 12mo, 405 pp. Muslin, \$2.

Domestic Practice of Hydropathy; with Fifteen Engraved Illustrations of important subjects, from Drawings by Dr. Howard Johnsun, with a form of a Report for the assistance of Patients in consulting their Physician by correspondence. By Edward Johnson, M.D. $12 \mathrm{mo}, 467 \mathrm{pp}$. Muslin, $\$ 2$.

Children : their Hydropathic Management in Health and Disease. A Descriptive and Practical Work, designed as a Guide for Families and Physicians. Illustrated with numerous cases. By Joel Shew, M.D. $12 \mathrm{mo}, 430 \mathrm{pp}$. $\$ 1.75$.

Midwifery and the Diseases of Women: a Descriptive and Practical Work. With the General Management of Childbirth, Nursery, etc. Illustrated with numerous Cases of Treatment. Same author. $12 \mathrm{mo}, 430 \mathrm{pp}$. Muslin, $\$ 1.75$.

Hydropathic Cook-Book; with Recipes for Cooking on Hygienic Principles. Containing also, a Philosophical Exposition of the Relations of Food to Health, the ('hemical Elements and Proximate Constitution of Alimentary Principles, the Nutritive Properties of all kinds of Aliments, the Relative Value of Vegetable and Animal Substances, the Selection and Preservation of Dietetic Material, etc. By R. T. Trall, M.D. $12 \mathrm{mo}, 226$ pp. Muslin, $\$ 1.50$.

Philosophy of the Water-Cure: a Development of the True Principles of Health and Longevity. By John Balbirnie, M.D. Illustrated; with the Confessions and Observations of Sir Edward Lytton Bulwer. 12mo. 50 cents.

Practice of the Water-Cure; with Authenticated Evidence of its Efficacy and Safety. Containing a Detailed Account of the vari ous processes used in the Water Treatment, a Sketch of the History and Progress of the Water-Cure, well authenticated cases of Cure, et.c. By James Wilson and James Manby Gully, M.D. 12mo, 144 pp. Paper, 50 cents.

Disedses of the Throat and Lungs, including Diphtheria and their Proper Treatment. By R. T. Trall, M.D. With illustrative engravings. $12 \mathrm{mo}, \mathrm{pp} .39$. Paper, 25 cents.

Water-Cure for the Million. The Processes of Water-Cure Explained in a practical and popular manner. 30 cents.

The True Healing Art; or, Hygienic vs. Drug Medication. 30 cts.

Sent prepaid by first post, at prices annexed. Local agents wanted. Address S. R. WELLS, 3S9 Broadway, New York. 


\section{THE INDISPENSABLE HAND-BOOK.}

How to Write.... How to Talk .... How to Rehave, and How to Do Business.

\section{COMPIETE IN ONI IARGE VOLUME.}

Tris new worik-in four parts-embraces just that practical matter-offact information whicn every one-old and young-ought to have. It will aid in attaining, if it does not insare, "success in life." It contains some 600 pages, elegantly bound, and is divided into four parts, as follows:

\section{How to Write:}

As . Mandal of Letter-Writing and Composition, is far superior to the coramon "Letter-Writers." It teaches the inexperienced how to write Business Letters, Fu.nily Letters, Friendly Letters, Love Letters, Notes and Cards, and Newspaper Articles, and how to Correct Proof for the Press. The rewspapers have pronounced it "Indispensable."

\section{How to Talk:}

No other Book contains so MUCh Useful Instroction oN THE subject as thls. It teaches how to Speak Correctly, Clearly, Fluently, Foreibly, Bloquently, and kffectively, in the Shop, in the Drawing-room; a Chairman's Guide, to conduct Debating Societies and Public Meetings; how to Spell, and how to Pronounce all nosts of Words; with Exercises for Declamation. The chapter on "Errors Corrected" is worth the price of the volume to every young man. "Worth a dozen grammars."

\section{How to Behave:}

This is a Mandal of Etiquette, and it is Believed to Be this best "MANNERS BOOK" ever written. If you desire to know what good manners require, at Home, on the Street, at a Party, at Church, at Table, in Conversation, at Places of Amusement, in Traveling, in the Company of Ladies, in Courtship, this book will inform vou. It is a standard work on Good Behavior.

\section{How to Do Business:}

Indispensable in the Counting-room, in the Store, in the Shop, oa the FARM, for the Clerk, the Apprentice, the Book Agent, and for Business Men. It teaches how to Choose a Pursuit, and how to follow it with success. "It teaches how to get rich honestly," and how to use your riches wisely.

How to Write-How to Talk-How to Behave-How to Do Business, hound in one large handsome volime, post-paid, for $\$ 225$.

Agents wanted. Addiress, S. R. WELLS, 389 Broadway, New York. 
OR,

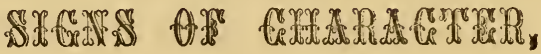

\section{As manifested in Temperament and External Forms, and especialiy in the Human Face Divine.}

\author{
Bx S. R. WELLS, Editor Phrenological Journal.
} Large 12mo, $768 \mathrm{pp}$. With more than 1,000 Engravings.

Hiustrating Physiognomy, Anatomy, Physiology, Ethnology, Phsenology, and Natural History.

Deded, considered system of Character-reading, based on the established truths of Physiology and $\mathrm{Phrenolngy,} \mathrm{and} \mathrm{confirmed} \mathrm{by} \mathrm{Ethnology,} \mathrm{as} \mathrm{well} \mathrm{as} \mathrm{by} \mathrm{the} \mathrm{peculiarities} \mathrm{of} \mathrm{individ-}$ uals. It is no abstraction, but something to be made useful; something to be practiced by everybody and in all places, and made an efficient help in that noblest of all studiesthe Study of Man. It is readily understood and as readily applied. The following are some of the leading topics discussed and explained in this great illustrated work:

Previous Systems given, including those of all ancient and modern writers.

General Principles of Physiognomy, or the Physiological laws on which character-reading is and must be basec.

Temperaments. - The Ancient Doctrines - Spurzheim's Description - The New Classification now in use here.

Practical Physiognomy.-General Forms of Faces-The Eyes, the Mouth, the Nose, the Chin, the Jaws and Teeth, the Cheeks, the Forehead, the Hair and Beard, the Complexion, the Neck and Ears, the Hands and Feet, the Voice, the Walk, the Laugh, the Mode of Shaking Hands, Dress, etc., with illustrations.

Ethnology,-The Races, including the Caucasian, the North American Indians, the Mongolian, the Malay, and the African, vith their numerous subdivisions: also National Types, each illustrated.
Physiognomy Applied-To Marriage, to the Training of Children, to I'ersona Improvement, to Business, to Insanity and Idiocy, to Health and Disease, to Classes and Professions, to Personal Improvement, and to Character-Reading generally. Utility of Physiognomy, Self-Improvement.

Animal Types. - Grades of Inteliigence, Instinct and Reason - Atimai Heads and Animal Types among Meu.

Graphomancy.-Character revealed in. Hand-writing, with Specimens-Palmistry. "Line of Life" in the human hand.

Character-Reading.-More than a hundred noted MIen and Women introduced-What Physiognomy says of them.

The Great Secret.-How to be IIealthy and How to be Beautiful-Mental Cosmetics-very interesting, very useful.

Aristotle and St. Paul.-A Mode: Head-Views of Life - Illustrative Anecdotes-Detecting a Rogue by his Face.

Nu sue can read this Book without interest, without real profit. "Knowledge is power " and this i. emphatically true of a knowledge of men-of human character. He who has it is "master of the situation ;" and anybody may have it who will, and find in It the "secret of success" and the road to the largest personal improvement.

Price, in one large Volume, of nearly 800 pages, and more than 1,000 eagravisgo, on wneel paper, handsomely bound in embossed muslin, $\$ 5$; in heavy calf, narh!w edyes, s; Tiurey morocco, full gilt. $\$ 10$. Agents may do well to canvass for this work. Firee by post. Please address, S. R. WELLS, 389 Broadway, New York. 


\title{
Works on Phrenology and Physiognomy,
}

\author{
Published by S. R. WELLS, 389 Broadway, N. Y.
}

"Good Boors For ALL."-Here are the best Works on these subjects. Each covers ground not covered by others. Copies of one or all will be sent by return post, on receipt of price. Please address as above.

American Plrenolosical \$our. NAL AND LIFE lllustrated. Devoted to Ethnology, Physiology, Phrenologs Physiognomy, Psychology, Biorraphy, Education, Art, Literature, with Measures to Reform, Elevate and Improve Mankind Physically, Mentally and spiritually. Edited by $\$$. R. Wells. Published monthly, in octavo form, at $\$ 3$ a year in advance, or 30 cents a number.

Annials of Plicenology and Physiognomy. One yearly $12 \mathrm{mo}$ volume. Price 25 cents for the current

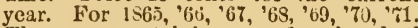
The seven containing over four hundred pages, many portraits and biographies of distinguished per'sonages, together with articles on "How to Study Phrenology," "Bashfulness, Diffidence, stammering," "The Marriage of Consins," ". Jealousy, Its Cause and Cure," etc. The seven bound in one volume, muslin, $\$ 1.50$.

Constitution of MIan. Considered in relation to External Objects. By Georas Combe. The only authorized American Edition. With Twenty Engravings, and a Portrait of the Author. SIuslin, \$1.75.

Cliart of Pliysiognomy rllusTraten. Designed for Framing and for Lecturers. Map form. 25 cents.

Defence of In renology ; Containing an Essay on the Nature and Value of Phrenological Evidence. A Vindication of Phrenolugy against the Attacks of its opponents, and a View of the Facts relied on by Phrenologists as proof that the Cerebellum is the seat of the reproductive instinct. By BOARDMAN. $\$ 1.50$.

Domestic Life, Thouglits on ; or, Marriage Vindicated and Free Love Exposed. By N. Sizer. 25 cents.

Education: Its elementary Principles founded on the Nature of Man. By J.G. Spurzhein, M.1. With an Appendix, containing the Temperaments, and a Brief Analysis of the Faculties. An excellent work. Illustrated. \$1.50.

Iducation and selformproveMENT CoMPlete. Comprising Physiology-Animal and Mental; Self-Culture and Perfection of Character; including the Management of Youth; Memory and Int dlectual Improvement. Complete in one large $12 \mathrm{mo}$ vol. Muslin, $\$ 4.00$.
Fow to Read Character. A New Illustrated Hand-Book of Phrenology and Physiognomy, for students and Examiners, with a Chart for recording the sizes of the different Organs of the Brain, in the Delineation of Character, with upwards of 170 Engravings. Latest and best. Paper, $\$ 1$. Muslin, $\$ 1.25$.

IIemory and Intellectial ImProverent, applied to Cultivation of Memory. Very useful. \$1.50.

Lecturea on Pliremology. By George Combe. With Notes. An Es. say on the Phrenolngical Mode of Inves. tigation, and a Historical Sketch. By BodizDian, MI.D. 1 vol. $12 \mathrm{mo}$. $\$ 1.75$.

Ifental science. Lectures on, according to the Philosophy of Phrenology. Delivered before the Anthropological Society. By G. S. WEaver. $\$ 1.50$.

Moral Plilosophy. By Georae Conbe. Or, the Duties of Man considered in his Individual, Domestic and Social Capacities. From the Edinburgh Edition. With the Author's latest cor. rections. $\$ 1.75$.

Natural Laws of IIan. Questions with Answer's. A Capital Work. By J. G. Spurzheim, M.D. Muslin, 75 cents.

Nety Plnysiognomy; or, Signs of Character, as manifested throngh Temperament and External Forms, and especially in the "Human Face Divine." With more than One Thousand Illustrations. By S. R. Welus. In three styles of binding. Price. in one $12 \mathrm{mo}$ volume, 768 pp., handsomely bound in muslin, $\$ 5 ;$ in heavy calf, marbled edges, $\$ S$; turkey morocco, full gilt, $\$ 10$.

Phrenology and the Scriptures. Harmony between Phrenology and Bible. By John Pierpont. 25 cents.

Phrenological Busts. Showing the latest classification, and exact locations of the Organs of the Brain, fully developed, designed for Learners. In this Bust, all the newly-uiscovered Organs are given. It is divided so as to show each Individual Organ on one side : and all the groups-Social, Executive, intellectual, and Moral-properly classified, on the other side. There are two sizes. the largest is sold in box, at $\$ 2.00$. The smallcr, at $\$ 1.00$. Sent by express. 
PErenoloxy Proved, llistraTED AND APPLIN. Emòracing an Analys's of the I'rimary Mental Powers in their Various Degrees of Development, and Location of the Phrenological Or$\mathrm{g}$ 'ns. Illustrated. $\$ 1.75$.

Self-rulture and Perfection of CHARACTER; Including the Training and Management of Children. $\$ 1.50$.

Selfanetructor in Pliremology AND P'Irysiology. With over One Hundred Engravings and a Chart for Phrenologists, for the Recording of Phrevological Developinents Paper, 50 cents. Muslin. 75 cents.

Symbolical tead and PlirenoLOGICAL MAP, on fine tiuted paper, for Framing. 25 cents.

Wells' Nevv Bescriptive Chart for Use of Examiners, giving a Delineation of Character. 25 cents.
Your Cliaracter from Youl LIKeNess. For particulars, how to havi pictures taken. inclose stamp for a cops of "Mirror of the Mind."

To Flaysicians, Lecturesa, and Examiners. We have a l'abinet of 40 Casts of Heads. selected from Our Mu seum. which are sold at $\$ 35.00$. Also a set of Phrenological Drawi"gs, on canvas, size of life, 40 in number. price $\$ 40.00$. A set of six Anatomical and Physiological plates, colured and mounted, $\$ 20$. A nother set of twenty. in sbeets. plain, \$35. Colored and mounted. $\$ 60$. Skeletons, from $\$ 10$ to $\$ 60$. Manikins, $\$ 250$ to $\$ 1000$. Portraits in oil from $\$ 5$ upwards. Woodcuta, $\$ 3.50$ to $\$ 5$. Sym. bolieal Heads, Electrotypes, 83 to $\$ 5$, and $\$ 7.50$, according to size.

All Works pertaining to the "ScIENCE of MAN," including Phrenology, Physiognomy, Ethnology, Psychology, Physiology, Anatomy, Hygiene, Dietetics, etc., suppli:d. Enclose stamp for Wholesale Terms to Agents. Address S. R. Wells, 389 Broadway, New York.

\section{Works on Physiology and Hygiene.}

IIt. has been said that, a man at Forty Years c Age, is either a "Physician or a Fool." - That at this Age, he ought to know how to treat, and take care of himself. These Works are intended to give instruction on "How to Live." How to avoid Diseases and of Premature Decay. They are practical, adapted to both People and Profession.]

natomical and Physiolorical Plates Arranged expressly for Leetures on Health, Physiology, etc. By R. T. T'rall, M. D. They are six in number, representing the normal position and life-size of all the internal viscera. magnified illustrations of the organs of the special senses, and a view of the nerves, arteries, veins, nusscles, etc. Fully colored, backed, and mounted on rollers. Price for the set, net $\$ 20$.

Avoidable Causes of Disease, INSANITY, AND DEFORMITY, including Marriage and its Violations. By Dr. John Ellis. \$2.

Children, their Management in Health and Disease. A Deseriptive and Practical Work. By Dr. Shew. \$2.75.

Diseases of the 'rinroat and LUNGs. With Treatmint. 25 cents.

\section{Comestic Practice of Irydro-} PATHY, with a form of a Report for the assistance of Patients in consulting their Physicians. By E. Johnson, M. D. $\$ 2$.

Family Gymakium. Containing the most improved methods of applying Gymnastic. ('alisthenic, Kinesipathic, ard Vocal Exercises, to the Development of the Bodily Organs. By. Dr. Irall. Many Illustrations. \$1.75.
Food and Diet. With observations on the Dietical liegimen suited for Disordered States of the Digestive Organs, 1)ietaries of the Principal Metropolitan Establisbments for Lunatics, Criminals, Children, the Sick, Paupers, etc. A thorough scientific Work. By Junathan Pereira, M. D. F. R. S. and L. S. Edited by Charles A. Lee, M. D. $\$ 1.75$.

Fruits and Farinacea, the ProPER FoOd OF MAN. Vegetarian. By John Smith. With Notes and Illustrations. By R. T. Trall, M.D. Muslin, $\$ 1.75$.

Hydropathic Cook Book. With Recipes for Cooking on Hygienic Principles. By Dr. Trall. $\$ 1.50$.

Tydropathic Encyclopedia. A System of Hydropathy and Hygiene. Embracing Outlines of Anatomy; Physiology of the Human Body; Hygienic Agencies, and the Preservation of Health; Theory and Practice; special Pathology, including the Nature, Causes, Symptoms, and Treatment of all known Diseases. Designed as a Guide to Fanni lies and Students, and a Text-Book for l'hysicians. By li. T. Trall, M.D. \$4.30. The most complete Work on the subject. 
Fainily Physician. A Ready Prescriber and Hygien .c Adviser. With Reference to the Nature, Causes, Prevention, and Treatment of Diseases, Accidents, and casualties of every kind. With a Glossary, and Copions Inuex. By Joel sh: v. M.D. Muslin, $\$ 1$.

Inangenent of Infancy, Physiological and Moral Treatment. By Andrew Combe, M. D. With Notes and a Supplementary Chapter. Muslin, \$1.50.

Inidwifery and the Diseases of Women. A Descriptive and Practical Work. With tlit general management of Child Birth, Nursery, etc. \$1.75.

MIovememt-Cure. An Exposition of the swedish Movement-Cure. Embrac. ing the History ald Philosophy of this System of Medical Treatment. with Exainples of Movements, and Diree ions for their Use in Various Forms of Chronic Diseases, lllustrated. By George H. Taylor, M. D. Musiin, \$1.75.

Notes on Beauty, Viogr and DeVELOPMENT; or, How to Acquire Plumpness of Form, Strength of Limb, and Beauty of Complexion. 12 cents.

Physiolory of Dioestion. Considered with relation to the Principles of Dietetics. Hy Andrew Combe, D.MI. Illustrated. 50 cents.

Dhilosophy of the Water-Cure. A Development of the true Principles of Health and Longevity. By John Balbirnic, M.D. 50 cents.

Practice of the Water-Cure. Containing a Detailed account of the various Baiting processes. 50 cents.

Physiology, Animal and Mental: Applied to the Preservation and Restoration of Health of Body and Power of Mind. Illustrated. Muslin, $\$ 1.50$.
Principles of Physiology applied to the Preservation of Healih and to the Improvement of l'hysical and Mertal Education. By Andrew Combe. $\$ 1.75$.

Science of Human Life, Lectires on TH\%. By Sylvester Graham. With a copious Index and B ographical Sketch. of the Author. 1llustrated. \$3.50.

sober and Temperate Life. The Dis courses and Letters of Louis Cornaro. With a Biography of the Author, who died at 150 years of age. 50 cents.

Tea and Coffee, their Physical, Intellectual, and Moral Effects on the system. By Dr. Alcott, 25 cents.

The Alcoholic Controversy. A Review of the Westminster Revievo on the Physiological Errors of Teetotalism. By Dr. Trall. 50 cents.

The Story of a Stomach. By a Reformed Dyspeptic. Paper, 50 cents; muslin, 75 cents.

Three Hours' School a Day. A Serious Talk with Parents. By William L. Crandal. Muslin, \$1.50.

Water-Cure in Chronic Diseases. An Exposition of the ('auses, Progres: and Terminations of Various Chronic Discases of the Digestive Organs, L.ungs, Nerves, and skin, and of their Treatment. With engraved View of the Lungs, Heart, Stomach, and Bowels. By J. M. Gully, M. D. \$2.

"A Special List" of 70 or more Privato Medical, Surgical and Anatomical Works, invaluable to those who need them, sent on receipt of stamp. Address S. R. W ells, $3 S 9$ Broadway, New York.

The REALER will greatly oblige by exhibiting this CATALOGUE to a neighbor, who would, perhaps, be glad to procure some of the Works; or, would like to become a subscriber to the Illustrated PhrenologiCAL JoURNAL, or engage in the sale of these publications.

\section{Works for Home Improvement.}

This List embraces just such Works as are snited'to every member of the familyold and young. These Works will serve as guides in Self-Improvement, and are aln ost indispensable to those who have not the advantages of a liberal education.

Aims and Aids ror Girls and Youny WoME. on the various Duties of Life, Physical, Intellectual, and Moral, SelfCuiture, Improvement. Dress, Beauty, Employment, the Home Relations, Duties to Young Men, Marriage, Womanhood, and Happiness. By Rev. G. S. Weaver. Muslin, $\$ 1.50$.
AEsop's Fables. The People's Pictorial Edition. Bealtifully illustrated with nearly Sixty Engravings. Cloth, gilt, beveled boards. Only $\$ 1$.

Benny. An Illustrated Poem. By Anna Chambers Ketchum. Published in the elegant style of Enoch Arden. A beanti fu. Christmas present. \$1.5j. 


\section{HYGEIAN HOME,} FLORENCE HIGH'S, N. J. Consulting Pirysicians.

\section{R. T. TRALL, M.D.,}

MARY A. BUTTS, M.D.,

MRS. HARRIET M. FORAN,
MISS SARAH FULLER, M.D.
Associate Physicians

JAMES FORAN, M.L. ,

M. E. BALL, M.D.

This model Health Institution is beantifully situated on the east. bank of the Delaware River, between Trenton and Philadelphia. The main building is two hundred and fifty feet in length, four stories high ; its rooms are large and pleasant, and it is abundantly supplied with

\section{PURE SOFT WATER FROM LIVING SIRINGS.}

A broad verandah, the entire length of the building, W:th ample fields, and a grove extending a mile along the river, afford all the facilities for promenading that cin be desired.

All curalle diseases are successfully treated without drug-medicine. Send stamp for circular.

\section{新品icnic tramily Sebool.}

A department of Hygeian Home is devoted to a Boarding School, where children can be taught all of the primary branches, music, \&c., and have their health properly cared for.

TERMs.-\$20 per month, or $\$ 200$ per year.

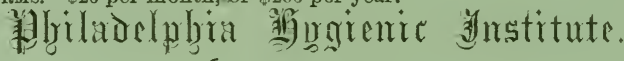

NO. I5I6 CHESTNUT STREET.

R. T. TRALL, M.D.,

MRS. E. S. CHOATE, M.D.,

\} Physicians.

JOSEPH WILLIAMS, M.D.,

Patients visited, and, when practicable, treated at their residences. The Physicians will respond to calls to lecture in city or country.

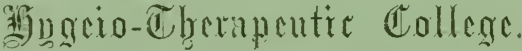

The regular lecture terms commence in the midale of November in each year, and contiume twenty weeks. This school is chartered by the Legislature, and legally authorized to confer the degree of M.D. Lailies and gentlemen are admitted on precisely equal terms.

TrRms.-Lecture Fees, $\$ 100$; Graduation Fee, $\$ 30$. After the first term, students or physiciaus may attend any subsequent term on the payment of $\$ 10$.

The Honorary Degree of the College will be conferred on properly qualified persons who cannot attend the lectures, on the payment of the diploma fee of $\$ 30$.

College Faculty and Teachers. R. T. TRALL, M.D., Institutes of Medicine, Patholngy and Therapentics. O. T. LI ES, M.D., Anatomy and Surgery. SUSANNAH W. DODDS, M.D., Physiology and Obstetrics. JAMES FORAN, M.D., Phrenology and Mental Science.

R. T. TRALL, JR., M.D., Music and Gymnastics.

II. E. BALL. M.D., Natural Plilosophy.

JOHN A. RYDER, M.D., Chemistry and Hygienic Agriculture.

For further information address,

$$
\text { R. T. TRALL, M.D., PRINCIPAL。 }
$$










\section{LIBRARY OF CONGRESS}

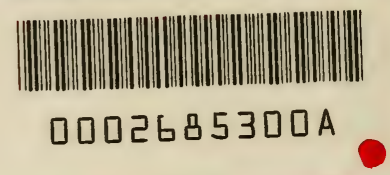

